\title{
High drug-loading nanomedicines: progress, current status, and prospects
}

\author{
This article was published in the following Dove Press journal: \\ International Journal of Nanomedicine \\ 31 May 2017 \\ Number of times this article has been viewed
}

\section{Shihong Shen \\ Youshen Wu \\ Yongchun Liu \\ Daocheng Wu}

Key Laboratory of Biomedical Information Engineering of Education Ministry, School of Life Science and Technology, Xi'an Jiaotong University, Xi'an, People's Republic of China
Correspondence: Daocheng Wu Key Laboratory of Biomedical Information Engineering of Education Ministry, School of Life Science and Technology, X'an Jiaotong University, Number 28 Xianning West Road, Xi'an, Shaanxi 710049 ,

People's Republic of China

Tel/fax +86298266 394I

Email wudaocheng@mail.xjtu.edu.cn

\begin{abstract}
Drug molecules transformed into nanoparticles or endowed with nanostructures with or without the aid of carrier materials are referred to as "nanomedicines" and can overcome some inherent drawbacks of free drugs, such as poor water solubility, high drug dosage, and short drug half-life in vivo. However, most of the existing nanomedicines possess the drawback of low drug-loading (generally less than 10\%) associated with more carrier materials. For intravenous administration, the extensive use of carrier materials might cause systemic toxicity and impose an extra burden of degradation, metabolism, and excretion of the materials for patients. Therefore, on the premise of guaranteeing therapeutic effect and function, reducing or avoiding the use of carrier materials is a promising alternative approach to solve these problems. Recently, high drug-loading nanomedicines, which have a drug-loading content higher than $10 \%$, are attracting increasing interest. According to the fabrication strategies of nanomedicines, high drug-loading nanomedicines are divided into four main classes: nanomedicines with inert porous material as carrier, nanomedicines with drug as part of carrier, carrier-free nanomedicines, and nanomedicines following niche and complex strategies. To date, most of the existing high drugloading nanomedicines belong to the first class, and few research studies have focused on other classes. In this review, we investigate the research status of high drug-loading nanomedicines and discuss the features of their fabrication strategies and optimum proposal in detail. We also point out deficiencies and developing direction of high drug-loading nanomedicines. We envision that high drug-loading nanomedicines will occupy an important position in the field of drug-delivery systems, and hope that novel perspectives will be proposed for the development of high drug-loading nanomedicines.
\end{abstract}

Keywords: nanomedicines, nanocarriers, high drug loading, fabrication strategy, optimum proposal

\section{Introduction}

Conventional free-drug-treatment methods mainly involve oral, subcutaneous, and intravenous administrations. A drug spreads all over the body via blood circulation, and accumulates to a certain concentration in the target location to achieve a therapeutic effect. However, the desirable effects of drug treatment often decrease, due to the disadvantages of free drugs, such as the short half-life in the body, high dosage, poor selectivity, side effects on normal tissues, and multidrug resistance. Additionally, considerable amounts of marketed drugs and many new chemical drug candidates (as much as $70 \%)^{1}$ are neither absorbed through the intestines nor circulated by intravenous injection because of low water solubility. For instance, paclitaxel (Ptx), an effective anticancer drug, has a solubility of $\sim 1 \mu \mathrm{g} / \mathrm{mL}$ in water, ${ }^{2}$ docetaxel, acknowledged as a drug with good solubility, has slightly higher solubility of $6-7 \mu \mathrm{g} / \mathrm{mL}$ in water. ${ }^{3}$ Therefore, solubilizing agents, such as dimethyl sulfoxide or surfactants, are typically 
added for systemic administration. ${ }^{4}$ However, such agents can still lead to neurotoxicity or other toxicities, even at very low dosages, thereby restricting the applications of free drugs. ${ }^{5}$ The application of nanomedicines, such as inert carrier-based nanomedicines, polymer-drug conjugates (PDCs), coordination polymer nanoparticles (NPs), and carrier-free nanomedicines, can partly overcome the potential problems of free drugs in therapy. Excellent properties of nanomedicines are simultaneously or sequentially obtainable as follows: 1) expanded application ranges of hydrophobic drugs as a result of enhanced water solubility; 2) long circulation times of drugs when dosed into the circulatory system; 3) targeted delivery of drugs at the sites of the diseases through nonspecific targeting, such as the enhanced permeability and retention (EPR) effect or specific NP-cell surface interactions; 4) responses to local stimulation of the target location, such as abnormal $\mathrm{pH}$, temperature, and ionic strength; 5) synergistic therapy via codelivery of multiple drugs at the same time and location; and 6) real-time monitoring of carrier (and drug) biodistribution and targeted accumulation. ${ }^{6,7}$ Since the first US Food and Drug Administration (FDA) approval of nanomedicine (liposomal amphotericin B in 1990), more than 24 nanomedicines have been approved for clinical use, with total sales exceeding US $\$ 5.4$ billion. ${ }^{8,9}$ The average cost and time required to develop a new nanomedicine (approximately \$20-\$50 million and 3-4 years) are significantly lower than for a new chemical drug (approximately \$500 million and over 10 years). ${ }^{10}$ Therefore, the design and development of novel nanomedicines have higher market value and application prospects than that for conventional chemical drugs.

According to the fabrication strategies of nanomedicines, high drug-loading nanomedicines can be divided into four main classes (Scheme 1): 1) nanomedicines with inert materials as carriers, including inorganic porous carrier-based

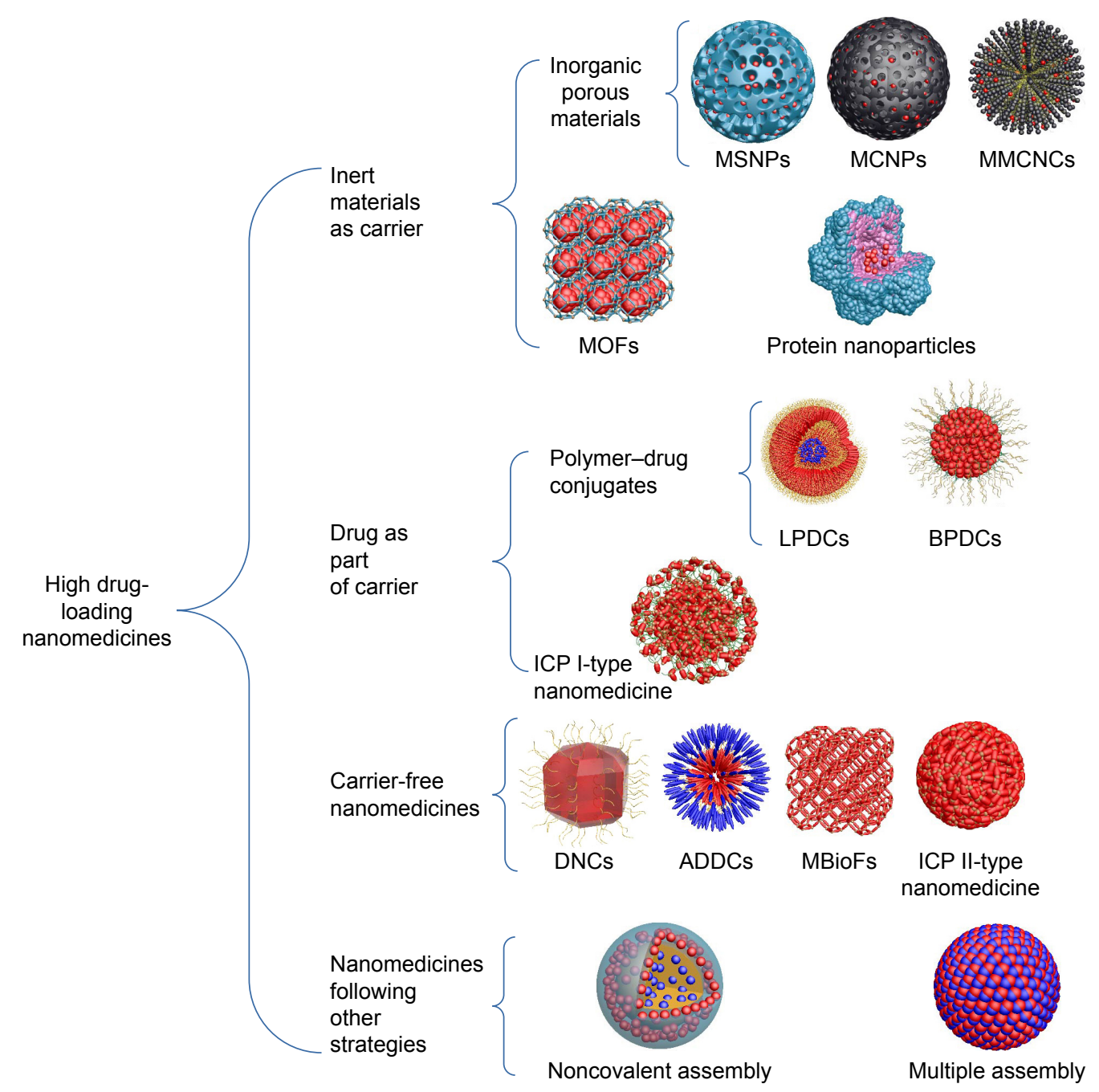

Scheme I Fabrication strategies of high drug-loading nanomedicines.

Abbreviations: MSNPs, mesoporous silica nanoparticles; MCNPs, mesoporous carbon nanoparticles; MMCNCs, mesoporous magnetic colloidal nanocrystal clusters; MOFs, metal-organic frameworks; LPDCs, linear polymer-drug conjugates; BPDCs, branched PDCs; ICP, infinite coordination polymer; DNCs, drug nanocrystals; ADDCs, amphiphilic drug-drug conjugates; MBioFs, metal-biomolecule frameworks. 
nanomedicines and absorption/desorption-type metal-organic framework (MOF)-based nanomedicines; 2) nanomedicines with drugs as part of the carrier, including linear and branched PDCs and infinite coordination polymer (ICP) I-type nanomedicines; 3) carrier-free nanomedicines, including drug nanocrystals (DNCs), amphiphilic drug-DCs (ADDCs), metal-biomolecule frameworks (MBioFs), and ICP II-type nanomedicines; and 4) nanomedicines following niche and complex strategies, such as aqueous noncovalent assembly and multiple assembly of drugs. For a visual comparison, the drug-loading content and drug-loading efficiency cited in this review are expressed according to the following equations:

Drug loading content (weight $[\mathrm{wt}] \%$ ) = $\frac{\text { Mass of the drug in nanomedicines }}{\text { Initial mass of the nanomedicines }} \times 100 \%$

Drug loading efficiency $(w t \%)=$ Mass of the drug in nanomedicines Mass of the drug in feed $\times 100 \%$

Drug-loading content and drug-loading efficiency are two important parameters of nanomedicines. Drug-loading content reflect the mass ratio of drugs to nanomedicines, and drug-loading efficiency reflects the utilization of drugs in feed during the nanomedicine-preparation process. In essence, drug-loading content is determined by the structure and physical and chemical properties of the carrier material; drug-loading efficiency is determined by the drug-loading mechanism, mass of the drugs in feed, and other experimental conditions. It is more difficult to obtain high drug-loading content than high drug-loading efficiency for most nanomedicines. Through physical and electrostatic adsorption, the drugloading process often results in low drug-loading efficiency, while through crystallization and covalent and coordinate bonds it often results in high drug-loading efficiency. Nanomedicines with high drug-loading content are usually prepared using processes with high drug-loading efficiency. ${ }^{11-14}$ If the space capacity of the carrier material is low, it is difficult to get high drug-loading content, even if the preparation process of nanomedicines shows high drug-loading efficiency. ${ }^{15-17}$ Taking into account most of the concepts investigated, high drug-loading efficiency may be necessary but not sufficient for a gain in high drug-loading content. In this paper, we focus mainly on drug-loading content, because this parameter is closely related to drug metabolism, side effects, extra burden, and therapeutic effect of the nanomedicines in vivo.

In most existing nanomedicines, inert carrier materials are mainly responsible for low drug-loading content (generally less than $10 \%) .{ }^{18-21}$ To administer a required drug dose in a target location, copious levels of carrier materials have to be used. For intravenous administration, the extensive use of these carrier materials may cause systemic toxicity, such as lipotoxicity, and impose an extra burden for patients to degrade, metabolize, and excrete these carriers. As such, FDA approval for most carrier-based nanomedicines is challenging to obtain, thereby limiting their clinical applications. On the premise of guaranteeing therapeutic effect and function, reducing or avoiding the use of carrier materials is a direct way of solving this problem. Moreover, it is easier for high drug-loading nanomedicines to achieve multidrug codelivery and combination therapy, which benefit from high drug loading. Given the advantages of combination therapy, including maximum therapeutic effect, minimum delay in induction of drug, and potential overcoming of multidrug-resistance mechanisms of tumors, ${ }^{22-24}$ multidrug-loaded high drugloading nanomedicines will become a new hot spot in the field of drug-delivery systems. Although considerable efforts have been devoted to the fabrication of various high drug-loaded nanomedicines, the therapeutic effects are not always satisfactory and many theoretical and actual problems remain unsolved. In addition, not enough attention is paid to the study of high drug-loading nanomedicines, and innovative strategies are seldom reported. Therefore, the research status of high drug-loading nanomedicines must be reviewed and summarized, and their prospects should be discussed. In this review, the current research development of high drugloading nanomedicines is investigated. The features of each fabrication strategy and proposals for possible optimization are discussed in depth. The inevitable role of high drugloading nanomedicines in future drug-delivery systems is highlighted. We also hope that this study will provide us with a new perspective that will lead us to design and develop novel high drug-loading nanomedicines.

\section{Nanomedicines with porous material as carrier}

In this section, nanomedicines with porous materials, including inorganic porous materials, MOFs and protein NPs as carriers, are investigated. All these carrier materials provide high surface areas, large pore volumes, and feasible drugloading methods, which contribute to high drug-loading capacity. The advantages and disadvantages of each material, as well as optimization options, are described.

\section{Inorganic porous materials as carriers}

To date, different kinds of inorganic porous materials, including mesoporous silica-based NPs (MSNPs), mesoporous 
Table I Overview of two strategies of fabricating high drug-loading nanomedicines with porous materials as carriers

\begin{tabular}{|c|c|c|c|c|c|}
\hline Strategy & Structure diagram & Main drug-loading mechanism & Application range & $\begin{array}{l}\text { Drug-loading } \\
\text { content }\end{array}$ & References \\
\hline $\begin{array}{l}\text { Inorganic } \\
\text { porous } \\
\text { materials as } \\
\text { carriers }\end{array}$ & $\begin{array}{l}\text { MSNPs/MCSNPs/MMSNPs } \\
\text { MCNPs }\end{array}$ & $\begin{array}{l}\text { Noncovalent electrostatic and/or } \\
\pi-\pi \text { stacking and/or hydrogen bond and/ } \\
\text { or hydrophobic interaction with carry } \\
\text { materials }\end{array}$ & $\begin{array}{l}\text { Hydrophobic drugs } \\
\text { mostly; peptides, } \\
\text { proteins, and gene } \\
\text { drugs sometimes }\end{array}$ & $\begin{array}{l}\leq 69.3 w t \% \\
\leq 59.7 w t \% \\
\leq 35 w t \%\end{array}$ & $\begin{array}{l}11,27-37, \\
39-42,48 \\
12,57,59-64, \\
63,73,78 \\
80-84,88, \\
90,95\end{array}$ \\
\hline $\begin{array}{l}\text { MOFs as } \\
\text { carriers }\end{array}$ & MOFs & $\begin{array}{l}\text { Coordinate bond and/or } \pi-\pi \text { stacking } \\
\text { and/or hydrophobic interaction }\end{array}$ & $\begin{array}{l}\text { Hydrophobic drugs } \\
\text { mostly; gas drugs } \\
\text { sometimes }\end{array}$ & $\leq 58.3 w t \%$ & $108-120$ \\
\hline $\begin{array}{l}\text { Protein NPs as } \\
\text { carriers }\end{array}$ & PNPs & $\begin{array}{l}\text { Covalent bond with protein scaffold and/ } \\
\text { or } \pi-\pi \text { stacking, hydrophobic interaction } \\
\text { with surface of PNPs and/or crystallization }\end{array}$ & $\begin{array}{l}\text { Hydrophobic drugs } \\
\text { mostly; peptides and } \\
\text { gene drugs sometimes }\end{array}$ & $\leq 44.9 w t \%$ & $122-126$ \\
\hline
\end{tabular}

Abbreviations: MCNPs, mesoporous carbon nanoparticles; MCSNPs, mesoporous calcium silicate nanoparticles; MMCNCs, mesoporous magnetic colloidal nanocrystal clusters; MMSNPs, mesoporous magnesium silicate nanoparticles; MOFs, metal-organic frameworks; MSNPs, mesoporous silica nanoparticles; PNPs, protein nanoparticles; wt, weight.

carbon NPs (MCNPs), magnetic colloidal NCs (MCNCs), mesoporous $\mathrm{TiO}_{2} \mathrm{NPs}^{25}$ and other inorganic porous materials, have been used to fabricate high drug-loading nanomedicines based on their intrinsic properties, such as large hollow interior, porous surface, and high surface:volume ratio. As summarized in Table 1, nanomedicines with inert material carriers can deliver different kinds of guest molecules. ${ }^{26}$ In general, drug molecules are loaded into nanocarriers with high loading content through noncovalent electrostatic, $\pi-\pi$ stacking, hydrogen bond, and hydrophobic interactions with carrier materials. In recent studies, drug molecules have been conjugated with the porous surface of carrier materials to acquire further increased drug-loading content and additional stimuli-responsive ability.

\section{Mesoporous silica-based materials as carriers}

Since Vallet-Regi et al proposed MCM41 as a drug-delivery system in 2001, ${ }^{27}$ MS-based materials, including MS, mesoporous calcium silicate, and mesoporous magnesium silicate, have been widely used in the fabrication of high drug-loading nanomedicines because of their intrinsic structure properties. The surface area and pore-volume ratio of MSNPs often exceeds $1,000 \mathrm{~m}^{2} / \mathrm{g}$ and $0.5-1 \mathrm{~cm}^{3} / \mathrm{g}$, respectively, which facilitates the loading of large amounts of drug molecules. ${ }^{28} \mathrm{Li}$ et al showed that MSNPs could effectively load ibuprofen, a typical anti-inflammatory drug, with high drug-loading content of up to $21.6 \% .{ }^{29}$ Moreover, MSNPs present a site-selective controlled-release pattern by surface functionalization via any of the following three methods: cocondensation (one-pot synthesis), grafting (postsynthesis modification), and imprint coating. ${ }^{30-32}$ For example, MSNPs functionalized with chitosan have a $\mathrm{pH}$-triggered release characteristic, due to the swelling effect of chitosan in acidic environments. ${ }^{33}$ This nanomedicine was used to deliver an oral sustained drug, carvedilol, with loading content and efficiency reaching $32.49 \% \pm 1.57 \%$ and $96.25 \% \pm 3.12 \%$, respectively. Coincidentally, MSNPs exhibit temperatureresponsive properties through a pore-capping copolymer poly-[N-isopropylacrylamide-co-1-butyl-3- vinyl imidazolium bromide]. ${ }^{34}$ When the temperature changes between $36^{\circ} \mathrm{C}$ and $40^{\circ} \mathrm{C}$, the pore copolymers of MSNPs swelled or shrank to load or release the encapsulated cytochrome $\mathrm{C}$. The drug-loading content of cytochrome $\mathrm{C}$ in this nanomedicine was $26.3 \%$ (Figure 1 ).

To enhance drug-loading content further, MSNPs with enlarged nanopores (E-MSNPs) and hollow MSNPs

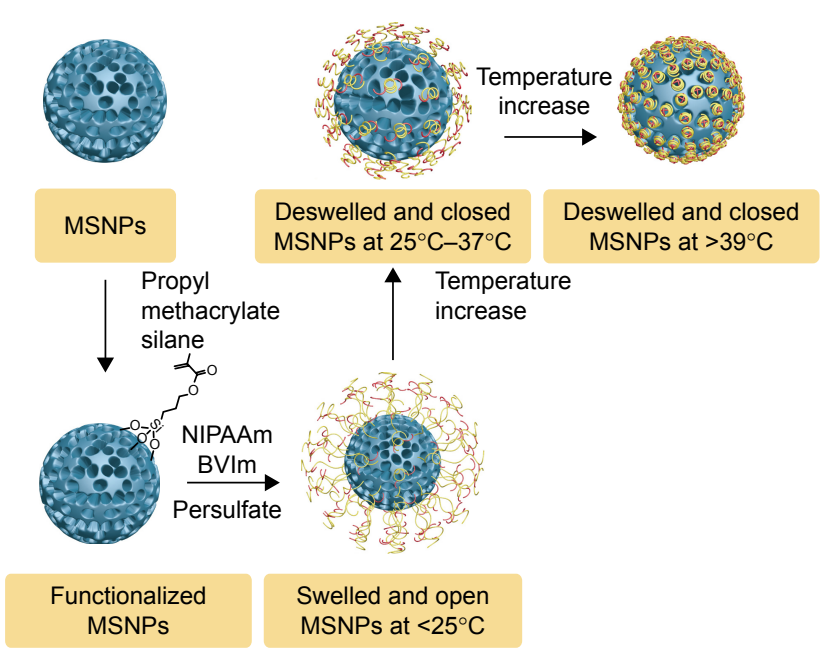

Figure I Preparation and temperature-dependent working mechanism of the cationic, thermosensitive, copolymer-capped MSNPs.

Abbreviations: MSNPs, mesoporous silica nanoparticles; NIPAAm, $\mathrm{N}$-isopropylacrylamide; BVIm, butyl vinylimidazolium. 
(HMSNPs) can be selected as carriers. Compared with conventional MSNPs, E-MSNPs and HMSNPs have larger pore volume, which can accommodate more drug molecules. ${ }^{35}$ Eltohamy et al proved that E-MSNPs had higher drug-loading content for cytochrome $\mathrm{C}$ than normal MSNPs (50 wt $\%$ in E-MSNPs and $35 \mathrm{wt} \%$ in normal MSNPs, respectively). ${ }^{36}$ Similarly, Zhu et $\mathrm{al}^{37}$ proved that HMSNPs had significantly higher drug-loading content for aspirin than conventional MCM48 and MCM41, which were two nanocarriers discovered by Mobil researchers in $1992 .{ }^{38}$ The drug-loading contents of HMSNPs, MCM48, and MCM41 were $25.1 \mathrm{wt} \%, 19.2 \mathrm{wt} \%$, and $16.6 \mathrm{wt} \%$, respectively, under the same experimental conditions. In following study, they added polyelectrolyte multilayers to the surface of HMSNPs to fabricate a stimuli-responsive controlled-release system. The polyelectrolyte multilayers of sodium polystyrene sulfonate and polycationic poly(allylaminium hydrochloride), prepared via a layer-by-layer method, yielded a drug-loading content of up to $41.64 \%$ for ibuprofen. ${ }^{39}$ Geng et al recently synthesized HMSNPs using hard template phenolic resin NPs to encapsulate two insoluble model drugs, namely carvedilol and fenofibrate. ${ }^{40}$ The resulting drug-loading contents for carvedilol and fenofibrate were $26.2 \% \pm 2.1 \%$ and $31.2 \% \pm 2.7 \%$ in normal MSNPs and $37.5 \% \pm 2.8 \%$ and $43.7 \% \pm 3.2 \%$ in HMSNPs, respectively. These findings indicate that HMSNPs have higher drug-loading content than normal MSNPs under the same conditions.

Another way to improve the drug-loading content of MSNPs is to conjugate drug molecules on the porous surface by covalent grafting or coordination bonds. Ebabe et al grafted two antioxidant molecules, caffeic acid and rutin, on to the surface of MSNP- $\mathrm{NH}_{2}$ through amino groups on MSNPs and carboxylic groups in antioxidant molecules. ${ }^{41}$ They reported that caffeic acid had drug-loading content of $44.2 \%$. Coordination is another feasible method. Farsangi et al prepared HMSNP-COOH carriers and loaded cisplatin in them via coordination bonds between carboxylic groups and $\mathrm{Pt}$ atoms in cisplatin molecules. ${ }^{42}$ These nanomedicines had a $\mathrm{pH}$-dependent release pattern with drug-loading content as high as $48 \mathrm{wt} \%$.

Mesoporous silicate-based NPs also have high drugloading capacity. In the early research, calcium silicate is regarded as a candidate for bone replacement biomaterial due to its good bioactivity. ${ }^{43-46}$ Then, its mesoporous form is applicable in protein/drug delivery for bone regeneration because of its high surface area and large pore volume and good biocompatibility. ${ }^{47} \mathrm{Wu}$ et al prepared ibuprofen-loaded mesoporous calcium silicate NPs with fine hierarchically nanostructure via a low-cost, surfactant-free sonochemical method. ${ }^{11}$ The drug-loading efficiency and drug-loading content of ibuprofen were as high as $86 \mathrm{wt} \%$ and $69.3 \mathrm{wt} \%$, respectively. When the ibuprofen-loaded nanomedicine released the absorbed load, the calcium silicate material gradually transformed to hydroxyapatite, due to its good bioactivity. Similarly, Wang et al synthesized hollow mesoporous magnesium silicate NPs via a facile template-etching route. ${ }^{48}$ These well-prepared NPs exhibited a significantly high drug-loading content of $68.15 \mathrm{wt} \%$ and held a sustainedrelease property, showing great potential for cancer therapy.

Despite the encouraging progress made in the research of MS-based high drug-loading nanomedicines, several major challenges still need to be addressed, such as the in vivo toxicity caused by MS-based carrier materials. Although silica is considered generally recognized as safe and has secured FDA approval for Phase I human clinical trials, ${ }^{49}$ in vivo studies have described dose-dependent toxicity, ${ }^{50}$ such as inflammatory response, ${ }^{51}$ liver injury, ${ }^{52}$ neurotoxicity, and pregnancy complications. ${ }^{53}$ Studies have shown that particle size, surface charge,${ }^{54}$ and surface functional groups also play significant roles in the cytotoxicity of MS-based carrier materials. ${ }^{55}$ Therefore, more careful and sufficient in vitro and in vivo studies are necessary to find the proper dose and type of MSNPs before clinical trials.

\section{Mesoporous carbon as carrier}

In contrast to the MSNPs already mentioned, MCNPs have even higher surface areas (as high as 2,000 $\mathrm{m}^{2} / \mathrm{g}$ ) and volume:mass ratios $\left(>1 \mathrm{~cm}^{3} / \mathrm{g}\right)$, which facilitate high levels of drug loading. ${ }^{56-58}$ In early reports, MC microparticles were used to improve the oral absorption of water-insoluble drugs with drug-loading content higher than 50\%.57,59-64 Applications of MCNP-based nanomedicines via intravenous administration have been quite limited, because of the following. First, ordered mesoporous carbons produced by carbonization of different chemical hydrocarbons usually have an undesirable size $(>1 \mu \mathrm{m}){ }^{65,66}$ for drug delivery $(<200 \mathrm{~nm}) .{ }^{67}$ Second, MCNPs exhibit poor dispersion in water under physiological conditions, due to their inherent hydrophobicity, which makes them impossible to use as carriers for intravenous drug administration. Finally, although some reports have shown that MCNPs have good biocompatibility, ${ }^{56,68}$ irregularly shaped MCNPs, such as carbon nanotubes or graphenes, can activate the complement system or induce immunotoxicity to some extent. ${ }^{69,70}$ With this limitation, MCNPs require further optimization to expand their application scope in drugdelivery systems. More recently, some MCNPs of $<100 \mathrm{~nm}$ 
diameter were obtained via template or hydrothermal method. Moreover, the hydrophilicity of MCNPs was improved by adding a hydrophilic cover, such as hyaluronic acid (HA) and polyethylene glycol (PEG), or introducing large amounts of oxygen-containing groups, such as hydroxyl, carboxyl, and sulfonic groups onto the surface. In one study, Liu et al successfully synthesized MCNPs with spherical morphology and uniform size $(71 \mathrm{~nm})$ via hydrothermal reaction of bacterial cellulose nanofibers $(30-50 \mathrm{~nm}) .{ }^{12}$ These MCNPs disperse well in aqueous solutions, because of the introduction of a large amount of hydrophilic functional groups, such as $-\mathrm{SO}_{3} \mathrm{H}$, phenolic $-\mathrm{OH}$, and $-\mathrm{COOH}$ groups, onto the surfaces. The drug-loading efficiency and drug-loading content of this nanomedicine for doxorubicin (Dox) were $93.4 \mathrm{wt} \%$ and $52.3 \mathrm{wt} \%$, respectively. In another work, spherical oxidized MCNPs with an average diameter of $90 \mathrm{~nm}$ were prepared through low-concentration hydrothermal treatment and mild oxidization. Then, PEGylated phospholipid 1,2-distearoyl-sn-glycero-3-phosphoethanolamine (DSPE)-methoxy-PEG ${ }_{2,000}$ was used as a protective layer added to the outer surface after Dox loading. The PEG layer on the surface prevented the premature and burst release of drugs in the circulation system, as well as helping to avoid recognition of the reticuloendothelial system. ${ }^{71,72}$ The drugloading content of this nanomedicine for Dox was as high as $59.7 \% \pm 2.6 \%$ under optimum conditions (Figure 2 ). ${ }^{73}$
Mesoporous carbon-based nanomedicines have two inherent advantages, due to their unique mesoporous structure and carbonaceous composition. First, mesoporous carbonbased high drug-loading nanomedicines often exhibit good $\mathrm{pH}$ sensitivity in drug-delivery systems. This feature is due to the fact that the adsorption of most anticancer drugs with aromatic structures, such as Dox, by carbonaceous structures via $\pi-\pi$ stacking and hydrophobic interactions is pH-dependent. Second, MCNPs serve as efficient photosensitizers with high absorption in the near-infrared region. ${ }^{74-77}$ Therefore, they function as promising nanocarriers in photothermal and chemical combination therapy. Zhou et $\mathrm{al}^{78}$ used these advantages to develop an effective dual-triggered (Hyal1/redox) chemophotothermal synergistic therapy nanomedicine, which presented efficient heat transformation for photothermal therapy. Research on MCNPs in drug-delivery systems is still in its infancy, and MCNPs face the following unsolved problems: 1) scalable synthetic strategies and standard methodologies to obtain MCNPs with suitable size and hydrophilic surfaces for intravenous administration; 2) unsuitability of traditional oxidation methods in the surface modification of MCNPs, because such techniques partially destroy the carbonaceous framework and the mesostructure of MCNPs; and 3) the limited application scope of MCNPs in nanomedicines and absence of applications of MCNPs in the field of gene and protein drug delivery, as opposed to MSNPs.

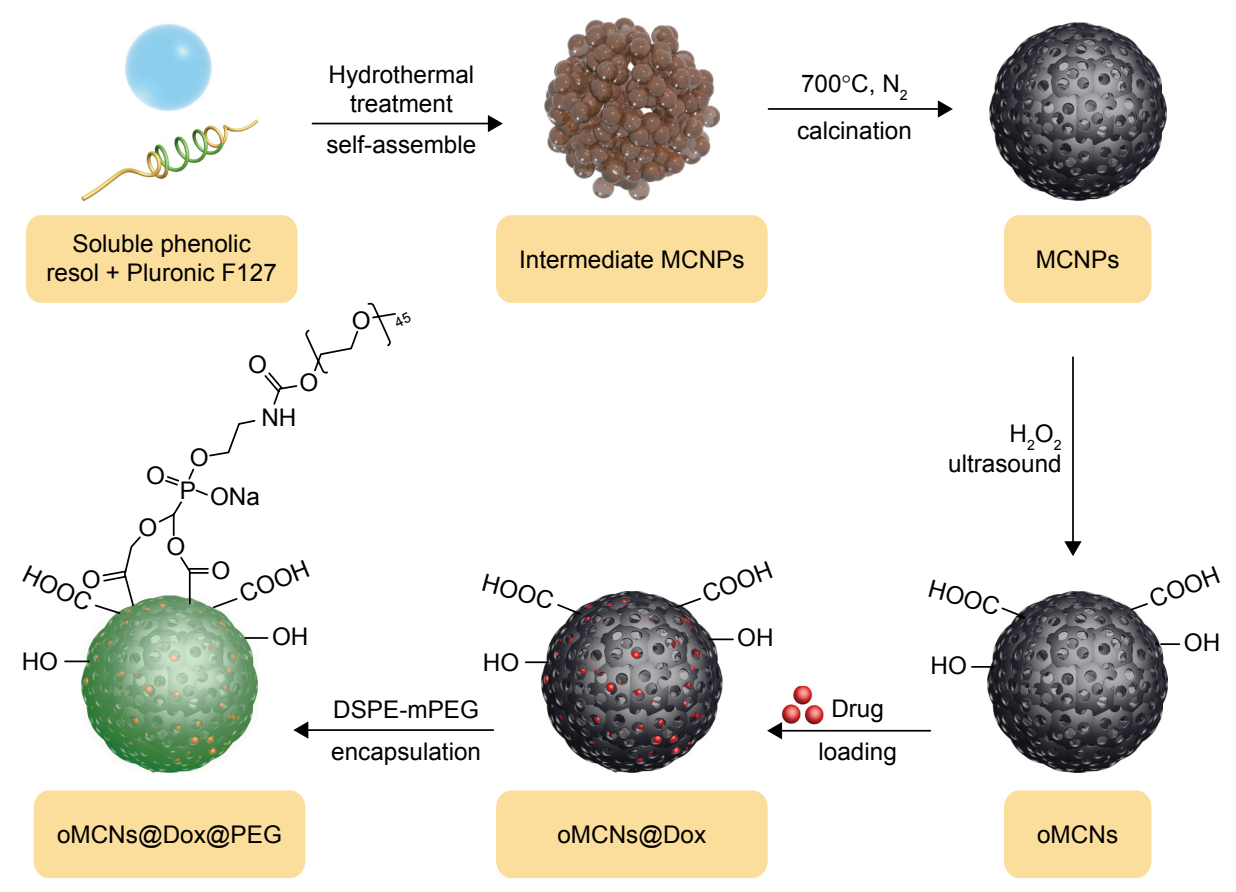

Figure 2 Synthesis, drug loading, and surface modification of MCNPs.

Abbreviations: MCNPs, mesoporous carbon nanoparticles; DSPE, I,2-distearoyl-sn-glycero-3-phosphoethanolamine; mPEG, methoxy polyethylene glycol; oMCNs, oxidized mesoporous carbon nanospheres; Dox, doxorubicin; PEG, polyethylene glycol. 
Mesoporous magnetic colloidal nanocrystal clusters Mesoporous/hollow MCNCs (MMCNCs/HMMCNCs) have drawn high attention in targeting drug-delivery systems during the past decade. HMMCNCs and MMCNCs are promising candidates for high drug-loading nanomedicines, because of their high magnetization, large surface area and pore volume, and excellent colloidal stability ${ }^{79-81}$ Compared with other inorganic porous materials, HMMCNCs and MMCNCs are known as the "magnetic motor" for sitespecific drug-delivery applications. ${ }^{82-84}$

The most common fabrication method of MMCNC-based nanomedicines begins with a combination of solvothermal reaction and electrostatic stabilization, ${ }^{85-89}$ and follows with drug loading via nanoprecipitation. ${ }^{80,88,90}$ Luo et al synthesized Ptx-loaded $\mathrm{Fe}_{3} \mathrm{O}_{4}$ MMCNCs using poly $(\gamma$-glutamic acid) as an electrostatic stabilization agent. ${ }^{88}$ The resulting MMCNC-based nanomedicine possessed high magnetization, large surface area $\left(136 \mathrm{~m}^{2} / \mathrm{g}\right)$ and pore volume $\left(0.57 \mathrm{~cm}^{3} / \mathrm{g}\right)$, excellent colloidal stability, prominent biocompatibility, acid degradability, and high drug-loading content of $35 \mathrm{wt} \%$ for Ptx.

The fabrication of HMMCNCs involves both templatebased $^{81,91,92}$ and template-free solvothermal reaction methods. ${ }^{80,92-94} \mathrm{Li}$ et al synthesized an HMCNC-based Dox-loaded nanomedicine with porous shell and tunable hollow chamber by a one-pot solvothermal process. ${ }^{81}$ This HMCNC carrier had a high surface area of $41.2 \mathrm{~m}^{2} / \mathrm{g}$ and pore volume of $0.36 \mathrm{~cm}^{3} / \mathrm{g}$, which contributed to high drugloading capacity. Furthermore, receptor-specific $\mathrm{pH}$-sensitive folate-modified polyacrylic acid (PAA-FA) was grafted on the surface of HMCNCs via a versatile ligand-exchange method, because folate molecules can target cancer cells that overexpress folate receptors and enhance the endocytosis capability of such cancer cells. This nanomedicine is stable under high $\mathrm{pH}$ and quickly releases Dox under low $\mathrm{pH}$. This site-specific targeting delivery was achieved by protonation and collapse of the PAA layers after cell internalization. ${ }^{95}$ The NPs presented drug-loading content of $24 \mathrm{wt} \%$ for Dox (Figure 3).

As described, novel inert magnetic NCs are promising nanocarriers, and their drug-delivery application is potentially feasible. Exciting progress has been made in MMCNC cluster-based nanomedicines, because of their high magnetization and large surface area. However, the fabrication of magnetic nanocarriers that demonstrate enhanced biocompatibility and excellent colloidal stability remains a challenge, which is critical for the application of magnetically driven drug delivery. Currently, in vivo toxicity studies and pharmacological experiments are scarce, and further studies are necessary.

\section{Absorption/desorption-type MOFs \\ as carriers}

MOFs, a class of coordination polymers, are another type of porous material (the other class of coordination polymer is an ICP particle that is covered in later sections). ${ }^{96} \mathrm{MOF}$ consist of transition metal ions/clusters and multidentate organic ligands, and are typically synthesized via coordinationdirected self-assembly processes under mild conditions (Figure 4).$^{97}$ Over the past two decades, MOFs have been applied in photonics, ${ }^{98}$ catalysis, ${ }^{99-101}$ biosensors, ${ }^{102,103}$ gas storage, ${ }^{104-107}$ and drug delivery. ${ }^{108-111}$ For drug delivery, the high drug-loading capacity of MOFs relies largely on three factors: 1) high surface area $\left(3,100-5,900 \mathrm{~m}^{2} / \mathrm{g}\right)^{108}$ and large, regular, accessible cages and tunnels; 2) good physicochemical stability in circulation and quick stimuli

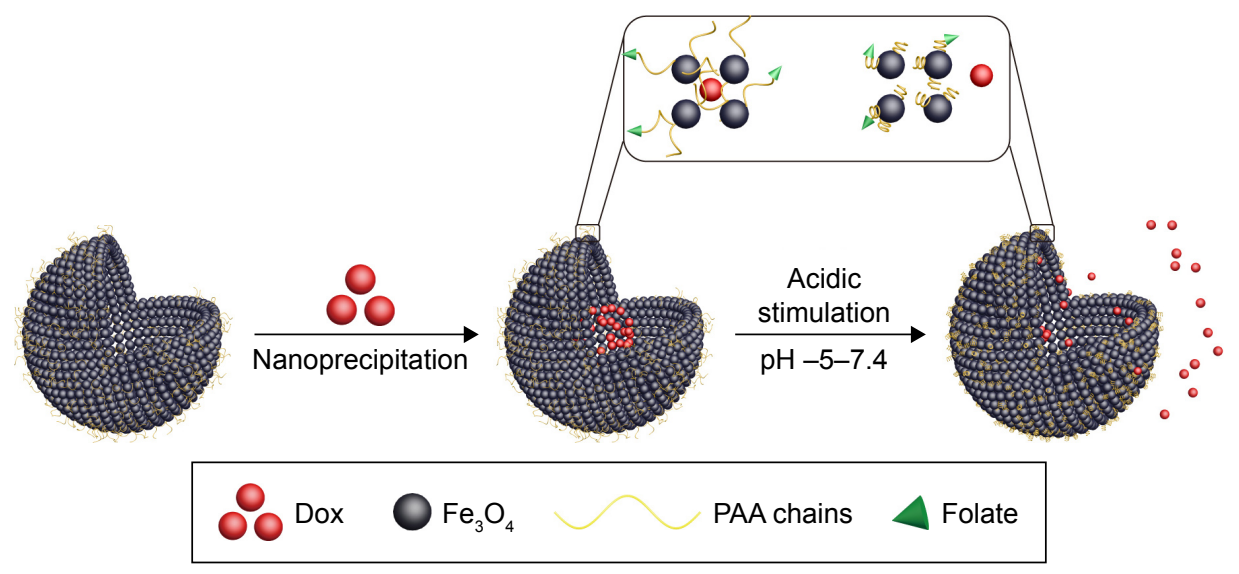

Figure 3 Dox encapsulation in HMCNCs and pH-stimulated release of Dox from folate-HMCNC-Dox. Abbreviations: Dox, doxorubicin; HMCNC, hollow magnetic colloidal nanocrystal; PAA, polyacrylic acid. 


\section{Strategy A: absorption/desorption-type MOF-based nanomedicine}

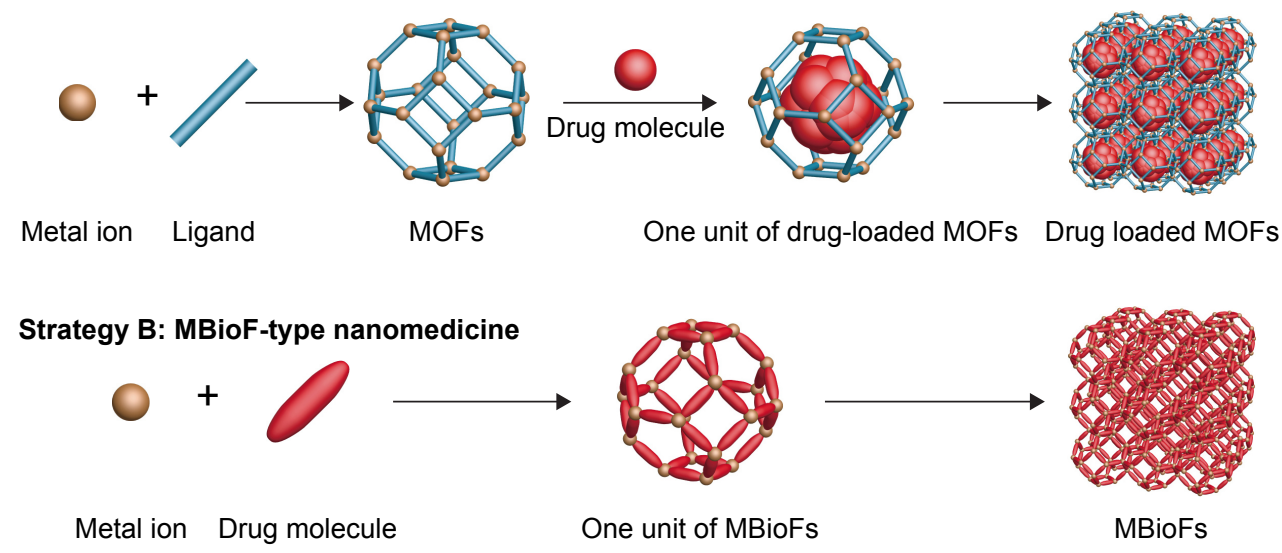

Figure 4 Formation of absorption/desorption-type MOF-based nanomedicine and MBioF-type nanomedicine by coordination-directed self-assembly processes. Abbreviations: MOF, metal-organic framework; MBioF, metal-biomolecule framework.

response, especially $\mathrm{pH}$ response; and 3) selectable metal ions with low toxicity (ie, Fe or $\mathrm{Zn}$ ) or metal ions associated with the mechanism of drug action (ie, Cu with gossypol). ${ }^{12}$ Two approaches can be considered in fabricating high MOF-based drug-loading nanomedicines. For absorption/ desorption-type MOF-based high drug-loading nanomedicines, drug molecules are absorbed in cages and tunnels of MOFs. For MBioFs, the bioactive drug molecules function as ligands that coordinate with the central metal atom. In this section, absorption/desorption-type MOF-based nanomedicines are summarized, whereas the latter are outlined in a following section.

Férey et al first reported absorption/desorption-type MOFbased nanomedicines in 2004. ${ }^{109}$ A model drug, ibuprofen, was absorbed by two dehydrated MOFs - chromium-based Material Institut Lavoisier (MIL)-100 and MIL101 ${ }^{109,113}$ effectively in hexane solution. X-ray powder diffraction and $\mathrm{N}_{2}$-adsorption experiments showed that both MOFs retained their excellent crystalline structures, and almost all the cages and tunnels were filled and/or blocked by the drug molecules. The drug-loading contents of ibuprofen for MIL100 and MIL101 were $58.3 \mathrm{wt} \%$ and $2.6 \mathrm{wt} \%$, respectively. The different absorption capacities between MIL100 and MIL101 were attributed to their fine structure inside the particles. The larger pore size of cages in MIL101 made it easier to absorb ibuprofen compared with MIL100. The size of ibuprofen is $6 \times 10.3 \AA$, whereas some cages in MIL100 were $4.8 \times 5.8 \AA$ (pentagonal), so the latter were not accessible for ibuprofen. The adsorption mechanism of ibuprofen in MIL100 and MIL101 was investigated by Babarao and Jiang through computational studies. ${ }^{114}$ They suggested that a part of the ibuprofen molecule penetrates MIL101 by forming coordinate bonds with unsaturated chromium molecules in the surrounding regions, and additional ibuprofen molecules weakly interact (ie, $\pi-\pi$ interactions and hydrophobic interaction) with existing ibuprofen molecules. The results of molecular simulation in this study were consistent with "two-stage" release profiles observed in Férey et al's work. Similarly, small-molecule drugs or gas drugs can be either chemisorbed by forming coordination bonds with transition metals or physically adsorbed into coordination polymers by weak intermolecular forces in absorption/desorption-type MOF-based nanomedicines.

For biological application, MOFs can be modified on the surface to increase size, decrease aggregation, and exhibit targeting performance. Horcajada et al developed a series of iron(III)-based MOFs (MIL53, MIL88A, MIL88Bt, MIL89, MIL100, and MIL101_ $\left.\mathrm{NH}_{2}\right)^{115-119}$ with engineered cores and surfaces for retroviral drug delivery. ${ }^{120}$ As expected, most of these MOFs (ie, azidothymidine triphosphate-loaded MIL101_NH $\mathrm{NH}_{2}$, cidofovir-loaded MIL101_NH ${ }_{2}$, urea-loaded MIL100, and urea-loaded MIL53) displayed high drugloading capacity of over $40 \mathrm{wt} \%$. PEG chains with only one terminal reactive group (amino or carboxyl) were firmly bound to the nanomedicine surface through coordinate covalent bonds of its amino or carboxyl end group with the metal centers. The PEG coating might control the nanomedicine size, protect the nanomedicines from aggregation, and escape sequestration by the reticuloendothelial organs.

Despite the research progress made, the potential application of MOFs in drug delivery is still in its infancy compared with other nanocarriers. Three major existing problems impede MOFs as mature high drug-loading nanomedicine carriers: 1) the relationship between the pore size of cages 
in different kinds of MOFs and the size of cargo drug molecules needs to be systematically studied and determined; 2) appropriate ligands and low-toxicity metal ions are needed to improve biocompatibility, and more efficient surface functionalization is needed to ensure longer blood circulation and better targeting effects; and 3 ) more careful and sufficient in vitro and in vivo experiments need to be conducted to expand the application prospects of MOFs in the biomedical field.

\section{Protein NPs as carriers}

As potential nanocarriers, protein NPs have intrinsic advantages, including synthesis in natural sources, precise size and uniformity, hollow inter structure, self-assembling ability, biocompatibility, and biodegradation. ${ }^{121}$ Hydrophobic drug molecules, peptides, and gene drugs are covalently conjugated to the hollow cavity of the protein scaffold or noncovalently loaded into the internal space. ${ }^{122-125}$ Generally, restricted by the number of attachment sites, most of the protein NP-based nanomedicines prepared by conventional chemical conjugation present the same drawback of lower drug-loading content $(<10 \%) .{ }^{122}$ One feasible way to enhance the drug-loading capacity of protein nanocarriers is designing and increasing the hydrophobic surface area of the protein NP. Inspired by transport mechanism of multidrug-efflux transporters, ${ }^{126}$ Ren et al ${ }^{123}$ implemented a biomimetic approach to enhance hydrophobic drug-protein interactions. Several virus-like protein NPs were redesigned and prepared via self-assembly of the $\mathrm{E}_{2}$ component of the pyruvate dehydrogenase multienzyme complex. Phenylalanine, one of the most hydrophobic amino acids, was systematically introduced to increase the hydrophobicity of $\mathrm{E}_{2}$ 's hollow cavity surface. The drugloading content of protein NPs for Dox reached 13.4\%, and the theoretical maximum loading content was thought to be as much as $44.9 \%$.

Although using protein NPs in the fabrication of high drug-loading nanomedicines is potentially feasible, a major concern with protein nanocarrier-based nanomedicines is their immunogenicity. When these nanomedicines are administered for the second time, elevated immune responses can occur and induce rapid clearance or neutralization or create potentially severe inflammatory responses. ${ }^{121}$ One way to bypass this problem is surface functionalization by introducing PEG and other coatings to reduce immunorecognition. ${ }^{71,72}$ The other is harnessing this natural effect and using it in immunobased treatments. ${ }^{127}$

\section{Nanomedicines with drugs as part of carrier}

Although absorption/desorption-type high drug-loading nanomedicines with inert porous carriers have attracted heightened interest in fabricating high drug-loading nanomedicines, the inherent limitations of this strategy cannot be ignored. Drug loading and release are mostly achieved by absorption and desorption, which strongly depend on the diffusion rate of drug molecules and drug-carrier interactions in the physiological medium. In the stage of nanomedicine design, the interactions are difficult to predict. Also, the degradation of the inert carrier material may lead to additional toxicity and impose an extra burden on patients to excrete the carriers.

For drugs with stable chemical properties in the circulatory system, the protective function from carriers is not essential. To overcome this limitation and further improve the drug-loading content of nanomedicines, the direct way is gradually reducing or replacing the use of carrier material. With this goal in mind, two popular strategies are proposed to fabricate such high drug-loading nanomedicines. One strategy is to form prodrugs by conjugating drug molecules with polymers, and another is to form ICP I-type nanomedicines, in which drug molecules function as ligands and coordinate with the central metal atom (Table 2). The drug and polymer are two indispensable excipients in high drug-loading nanomedicine. Without one of these, the nanostructures cannot be maintained.

Table 2 Overview of two strategies of fabricating high drug-loading nanomedicines with drug as part of carrier

\begin{tabular}{|c|c|c|c|c|c|}
\hline Strategy & Structure diagram & $\begin{array}{l}\text { Main drug-loading } \\
\text { mechanism }\end{array}$ & Application range & $\begin{array}{l}\text { Drug-loading } \\
\text { content }\end{array}$ & References \\
\hline $\begin{array}{l}\text { Polymer-drug } \\
\text { conjugates }\end{array}$ & $\begin{array}{l}\text { (9) Linear polymer-drug conjugate } \\
\text { Branched polymer-drug conjugate }\end{array}$ & $\begin{array}{l}\text { Covalent bond with } \\
\text { polymer }\end{array}$ & $\begin{array}{l}\text { Hydrophobic drugs mostly; } \\
\text { codelivery with hydrophilic } \\
\text { drug/gene drugs sometimes }\end{array}$ & $\begin{array}{l}\leq 58 w t \% \\
\leq 45 w t \%\end{array}$ & $\begin{array}{l}131-135 \\
13,136-143 \\
145-154,156-158\end{array}$ \\
\hline $\begin{array}{l}\text { ICP I-type } \\
\text { nanomedicines }\end{array}$ & (17) ICP I-type nanomedicines & Coordinate bond & $\begin{array}{l}\text { Drugs with complexing } \\
\text { ability (both hydrophobic } \\
\text { drugs and hydrophilic drugs) }\end{array}$ & Not shown & $160,161,164,165$ \\
\hline
\end{tabular}

Abbreviations: ICP, infinite coordination polymer; wt, weight. 


\section{Polymer-drug conjugates}

Compared with the physical encapsulation of drug molecules in inert carriers, PDCs, such as liner and branch types, are excellent candidates for high drug-loading nanomedicines, because of their limited usage of inert carrier materials and self-assembly abilities. In addition to the common advantages of other nanomedicines already mentioned, the smart covalent links between the drugs and polymers endow them with multiple advantages: 1) stimuli-triggered release and targeted delivery; 2) protection of drugs from leakage and premature release during intravenous administration; 3) altered drug pharmacokinetics in the whole organism and even at the subcellular level, which may enhance the drug's therapeutic value; and 4) additionally loading hydrophilic drugs into the core of micelles to achieve multidrugcombination therapy. For stimuli-responsive PDCs, $\mathrm{pH}$-responsive types are the most frequently used. Several pH-responsive covalent links, such as acetal, orthoester, hydrazone, imine, cis-acotinyl, and oxime, are common, due to their rapid hydrolysis in the endosomal compartment ( $\mathrm{pH}$ about 5). Moreover, a reduction-response covalent link disulfide depends on different redox potentials between the extra- and intracellular environments, especially in tumor cells. ${ }^{128-130}$

\section{Linear polymer-drug conjugates}

As the name suggests, linear PDCs are block copolymers that have a simple linear monomeric structure. Shen et al formed dual-drug-loading nanomedicines by conjugating one or two strong hydrophobic camptothecin (CPT) molecules to a very short oligomer chain of oligoethylene glycol (OEG) to form biodegradable ester bonds (Figure 5). ${ }^{131}$ The amphiphilic prodrugs OEG-CPT and OEG-DiCPT self-assemble into 100-200 nm liposome-like nanocapsules in aqueous solutions. The drug-loading contents for CPT were $40 \mathrm{wt} \%$ and $58 \mathrm{wt} \%$ in OEG-CPT and OEG-DiCPT, respectively, with undetected burst releases for both. Meanwhile, the liposomelike structures further loaded a water-soluble Dox $\mathrm{HCl}$ salt via a dialysis mechanism similar to drug loading into conventional liposomes. The drug-loading efficiency and drug loading content of Dox $\mathrm{HCl}$ were $85 \%$ and $18.5 \mathrm{wt} \%$, respectively. Once inside the cells, the Dox HCl-loaded amphiphilic CPT prodrug liposomes released both CPT and Dox $\mathrm{HCl}$, thereby providing synergistic cytotoxicity to cancer cells, as confirmed by high in vitro and in vivo antitumor activities. Similarly, Zhang et al synthesized a nanomedicine by conjugating the hydrophobic drug SN38 (7-ethyl-10-hydroxy-CPT), the active metabolite of CPT, to a low-molecular-weight OEG via an ester bond. The amphiphilic OEG-SN38 monomer self-assembled into micelles with a hydrodynamic diameter of $28.74 \pm 2.51 \mathrm{~nm}$, and a high drug-loading content of $36 \mathrm{wt} \%$ for SN38 was obtained. ${ }^{132}$ Gou et al ${ }^{133}$ anchored hydrophobic Dox to a lowmolecular-weight $\mathrm{PEG}$ chain via a $\mathrm{pH}$-responsive covalent hydrazine bond to form a linear amphiphilic PDC - PEGDox. This amphiphilic prodrug self-assembled into micelles with a diameter of about $125 \mathrm{~nm}$ in aqueous solution, and the drug-loading content for Dox was as high as $46 \mathrm{wt} \%$. Once the nanomedicines were taken up by cells via endocytosis, the hydrazine bonds were hydrolyzed in the acidic environment of the endosomal compartment, and the Dox molecules were simultaneously released.

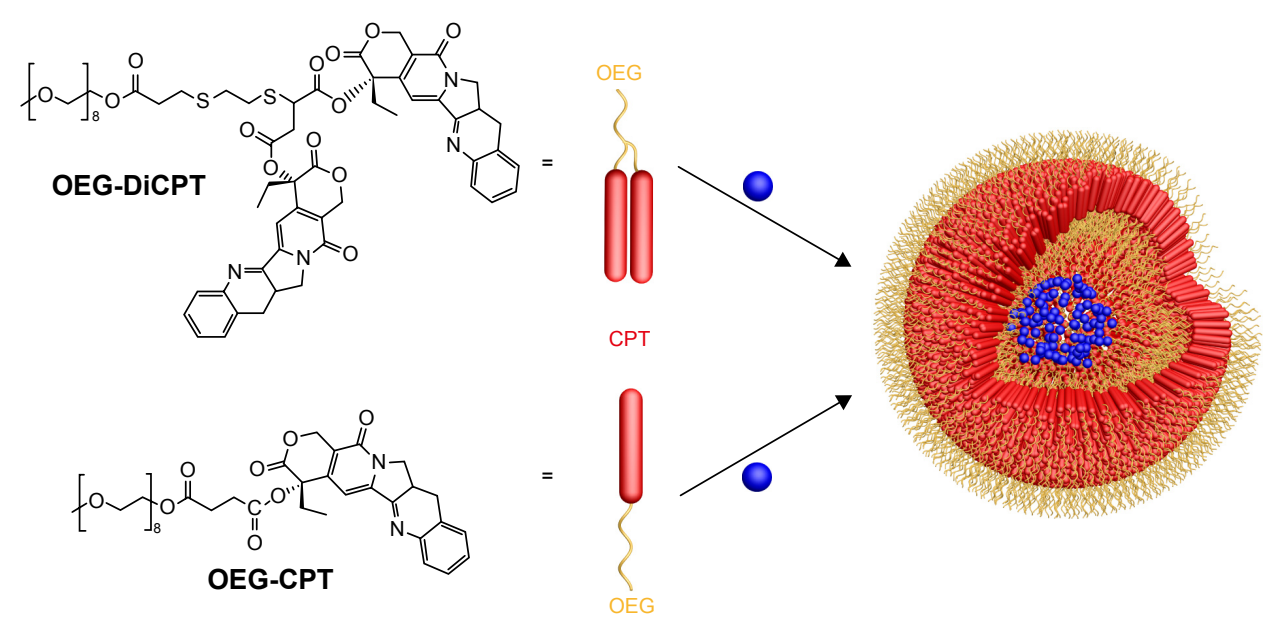

Figure 5 Amphiphilic CPT-polymer conjugates (OEG-CPT and OEG-DiCPT) and their self-assembly into nanocapsules to load other hydrophilic drug. Note: OEG-DiCPT means two CPT molecules were conjugated to one OEG molecule.

Abbreviations: CPT, camptothecin; OEG, oligoethylene glycol. 
Furthermore, PDC prodrug micelles can achieve targeted delivery by introducing targeting ligands, such as carbohydrates, folate, transferrin, peptides, and HA, onto the surfaces. ${ }^{134}$ For example, Guo et al synthesized a linear PDC FA-PEG- $b$-poly- $\varepsilon$-caprolactone (PCL)-hydrazone-Dox - to form $\mathrm{pH}$-sensitive folate-functionalized nanomedicines. ${ }^{135}$ The FA-PEG- $b$-PCL-hydrazone-Dox conjugates selfassembled into micelles with a hydration diameter of $70.9 \mathrm{~nm}$, according to dynamic light-scattering measurements. In these micelles, Dox molecules anchored to PCL via hydrazone bonds functioning as the hydrophobic part, whereas PEG served as the hydrophilic part. The FA layer on the surface of micelles facilitated the endocytosis of the folate receptor-overexpressing tumor cells.

\section{Branched polymer-drug conjugates}

Compared with linear PDCs, branched PDCs, including branched star PDCs, hyperbranched PDCs, dendrimer PDCs, and brush PDCs, exhibit controllable supramolecular morphologies, self-assembly behavior, and thermal, mechanical, rheological, and solution properties. ${ }^{136-139}$ All properties render branched PDCs viable for high drugloading nanomedicines.

Branched star polymers are branched polymers containing several linear chains attached to a central core. Star PDCs often have a compact structure, globular shape, and large surface; they also possess enhanced solubility, low melting viscosity, unique rheological properties, and a large number of drug-binding sites. ${ }^{140-143}$ All these excellent properties depend on the arm's molecular weight. ${ }^{144}$ Kowalczuk et al ${ }^{145}$ synthesized core-shell-type star polymer-cisplatin conjugates with a branched poly( $p$-[iodomethyl]styrene) acting as a hydrophilic core and PAA arms functioning as a hydrophilic shell. These star-type PDCs exhibited "unimolecular micelle" behavior in aqueous solution, and were globular with a hydration diameter of 12.9-14 $\mathrm{nm}$. The cisplatin molecules were loaded into the unimolecular micelles via the coordinative bonds between the platinum atoms of cisplatin molecules and high density of carboxyl groups on PAA arms. The drug-loading content for cisplatin was $45 \mathrm{wt} \%$. In vitro experiments showed lower cytotoxicity that was consistent with the sustained release of cisplatin molecules and slower cellular uptake of conjugated prodrug micelles compared with free cisplatin. Some examples of star PDCs utilized for nanomedicine fabrication following this strategy have been presented in the literature. ${ }^{146-149} \mathrm{In}$ a recent study, Liang et al designed $\mathrm{pH}$-sensitive star polymer-Dox conjugates, in which a triblock copolymer 2-(N,N-dimethylaminoethyl)- methacrylate-co- $p$-(methacryloxyethoxy)benzaldehyde-co2,2-dithiodiethoxyl dimethacrylate served as a hydrophilic core and poly(6-O-methacryloyl-D-galactopyranose) arms acted as a hydrophilic shell. ${ }^{150}$ Instead of loading drug molecules on the arm as previously mentioned, Dox molecules in this nanomedicine were loaded into the hydrophilic core through acidic-labile imine bonds between the aldehyde groups in $p$-(methacryloxyethoxy)benzaldehyde and the primary amines in Dox molecules. The drug-loading content of Dox in this nanomedicine was controllable in the range of 7.3-37.6 wt $\%$, depending on the different grafting degrees of Dox. These star polymer-Dox conjugates self-assembled into unimolecular micelles with average diameters of 30-50 nm in aqueous solution. Dox molecules were quickly released at $\mathrm{pH} 5$ and 6 due to the acid lability of aromatic imine linkage between the Dox molecule and star polymer. All these properties were desirable for drug delivery.

Hyperbranched polymers (HBPs) are another kind of branched polymer with a highly three-dimensional dendritelike architecture, and their degree of branching is 0.4-0.6 ( 0 for linear polymer and 1 for dendrimer). Similar to branched star polymers, HBPs have serious adjustable physicochemical properties, such as molecular entanglement, solution viscosity, solubility, host-guest interaction capacity, and self-assembly behavior, caused by their modifying branches, end groups, and controllable degree of branching. Given these beneficial properties, HBPDCs are excellent candidates for high drug-loading nanomedicine fabrication. ${ }^{151-153}$ Prabaharan et al ${ }^{154}$ synthesized the first HBPDC nanomedicines in 2009. In their work, a folate-targeting unimolecular micelle nanomedicine was synthesized, namely Boltorn H40-poly(L-aspartate-doxorubicin)- $b$-PEG/FA-conjugated PEG (H40-P[LA-Dox]-b-PEG-OH/FA). This nanomedicine contained a commercial aliphatic dendritic polyester Boltorn H40 core, hydrophobic poly(L-aspartate) inner arm, and a hydrophilic PEG and FA-conjugated PEG outer arm. Dox molecules were conjugated to the inner arm through a $\mathrm{pH}-$ sensitive hydrazone linker, resulting in a drug-loading content of $16 \mathrm{wt} \%$ for Dox. This block polymer self-assembled into micelles with sizes of 17-36 nm under dynamic light scattering and 10-20 nm under transmission electron microscopy. Following this strategy, Ye et al fabricated HBP-cisplatin conjugates based on hyperbranched polyglycerols (HPGs). ${ }^{13}$ In this system, HPGs were modified with hydrophobic alkyl $\left(\mathrm{C}_{8} / \mathrm{C}_{10}\right)$ chains into the core, derivatized with methoxy PEG (MePEG) onto the surface, and further functionalized with carboxylate groups on MePEG chains to conjugate and release cisplatin. The drug-loading efficiency of cisplatin was 
$100 \%$, and its drug-loading content was adjusted depending on the conjugated carboxylate levels. Respectively, the drug-loading content of $\mathrm{HPG}-\mathrm{C}_{8} / \mathrm{C}_{10}-\mathrm{MePEG}_{6.5}-\mathrm{COOH}_{113}$ was $10 \mathrm{wt} \%$, whereas that for HPG-C8/10-MePEG6.5COOH348 was $20 \mathrm{wt} \%$. These HBP-cisplatin conjugates self-assembled into micelles with hydrodynamic diameters of 5-10 nm. These conjugates demonstrated $\mathrm{pH}$-triggered release behavior caused by the coordinate bond between cisplatin and carboxylate groups on MePEG chains. In vitro experiments showed that these nanomedicines presented good biocompatibility and antitumor effects.

Segmented polymers are a large family. Depending on the chemical differences among main chains, side chains, and grafting density of the side chains, the family of segmented polymers is classified as follows: graft polymer, in which the side chains have a different chemical nature from the main chains and low grafting density; brush-like polymers, in which the side chains have a different chemical nature from the main chains and high grafting density; and comb-like copolymers, in which the side chains have a similar chemical nature to the main chains and lower grafting density than brush-like polymers. ${ }^{155}$ Graft and brush-like polymers are excellent candidates for high drug-loading nanomedicine fabrication, depending on their side chains' selectability and modifiability. Xu et al reported a novel graft polymer-Dox conjugate with a Dox-loading content as high as $40 \mathrm{wt} \%$, namely, PEG monomethylether- $b$-poly(methacrylamide tert-butyl carbazate-Dox) (MPEG- $b$-Dox) (Figure 6). ${ }^{156}$ The MPEG in this conjugate functioned as the hydrophilic part, and methacrylamide tert-butyl carbazate, which was conjugated to Dox via an acid-labile hydrazine bond, acted as the hydrophobic part. The amphiphilic conjugates selfassembled into micelles with average hydrodynamic size of $80 \mathrm{~nm}$. These conjugates also showed minimal drug release at $\mathrm{pH} 7.4$ and high Dox release at $\mathrm{pH}$ 5, following the previously mentioned mechanism. In parallel, Zou et al synthesized a brush PDC, PLA-g-Ptx/PEG, through azidealkyne click reaction of acetylene-functionalized PLA with azide-functionalized Ptx and PEG. The drug-loading content of Ptx reached nearly $23.2 \mathrm{wt} \%$. $^{157}$

Similarly to linear PDC liposomes, branched PDC unimolecular micelles with hydrophobic inner domain can further effectively encapsulate hydrophobic substances into their cores for imaging or codelivery. Tai et al ${ }^{158}$ reported $\gamma$-CPT and Dox dual-drug-loaded nanomedicines prepared via polymerization of $\gamma$-CPT-glutamate $N$-carboxyanhydride on a PEG-based backbone via ring-opening polymerization. The amphiphilic conjugates self-assembled into unimolecular micelles with average hydrodynamic size of $50 \mathrm{~nm}$. Dox molecules were then loaded into the hydrophobic core through physical interactions, such as $\pi-\pi$ stacking. The drug-loading contents of CPT and Dox were $25.1 \mathrm{wt} \%$ and $30 \mathrm{wt} \%$, respectively. An in vivo study demonstrated that dual-drug-loaded nanomedicines displayed significant synergistic effect on lung cancer-xenograft mice.

PDCs are an emerging one-component strategy for high drug-loading nanomedicine fabrication. This one-component feature with drug as part of carrier is essentially a doubleedged sword: 1) for a particular PDC, the influence of the covalent links between drug molecules and biodegradable polymers to drug pharmacokinetics cannot be predicted; 2) the drug-release process can be complicated, which often involves both the nanostructure dissociating into monomeric units and the chemical breakdown of the linker; and 3) the choice of degradable linkers significantly affects the release mechanism of free bioactive drug from assembled nanostructures.

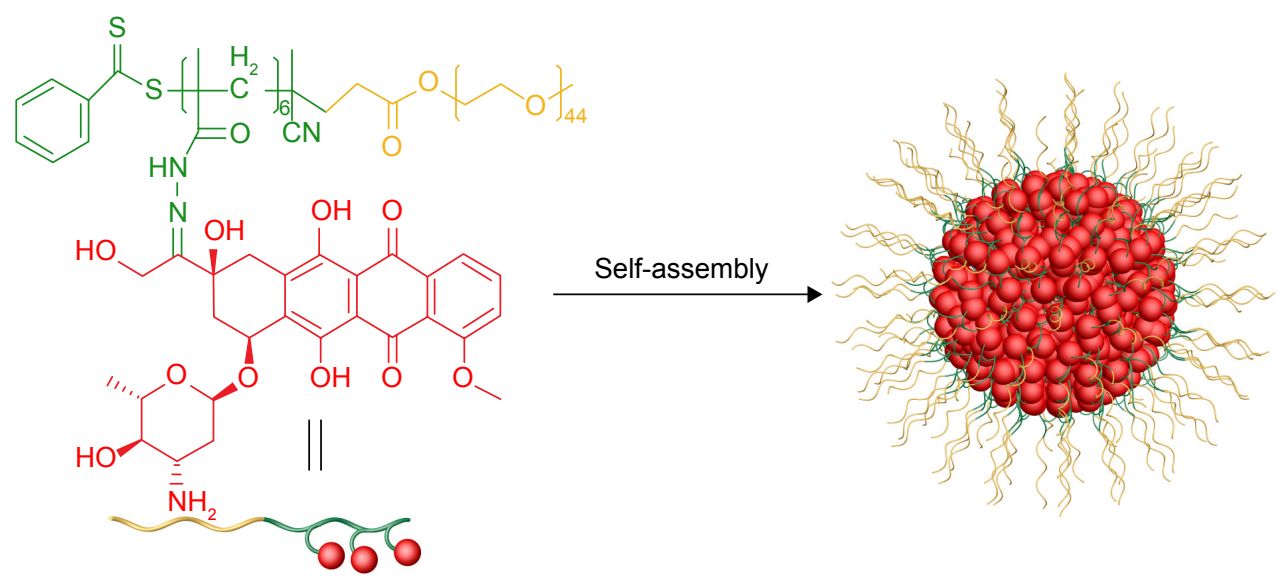

Figure 6 Formation of mPEG-b-Dox micelles.

Abbreviations: mPEG, methoxy polyethylene glycol; Dox, doxorubicin. 


\section{ICP I-type nanomedicines}

ICPs are one of the classes of coordination polymers. Compared with conventional MOF-based nanomedicines, ICPtype high drug-loading nanomedicines often exhibit certain additional advantages. The ICP-type nanomedicines have a trimmable size and well-defined shapes, ${ }^{159}$ therefore, a desired particle size can be obtained for intravenous injection compared with absorption/desorption-type MOF-based nanomedicines and MBioFs. The $\mathrm{pH}$-responsive point of nanomedicines can move to a targeted location without any additional dramatic alterations in the polymeric structure, due to the controllable degree of polymerization, chain monodispersion, intermolecular forces, and drug-metal coordination bonding strength. ${ }^{160,161}$ Several conventional anticancer drugs with autofluorescence often have tunable fluorescence when coordinating with central metal atoms. ${ }^{162,163}$ ICP-type nanomedicines are believed to be suitable candidates for computational design and combinatorial chemistry for drug content-specific nanomedicine development, because of their high drug-loading content and efficiency. ${ }^{164}$ This section outlines recent advances in ICP I-type high drugloading nanomedicines that consist of metal atoms and two kinds of organic ligands, with one of the ligands being the drug molecule.

The first use of ICPs in drug-delivery systems was in 2011 by Xing et al. ${ }^{164}$ They defined ICP I-type nanomedicines as "host metal-ligand coordination polymer" and ICP II-type nanomedicines as "metal-ligand coordination polymer". As illustrated in Figure 7, in ICP I-type nanomedicine, host ligands and drug molecules were coordinated with metal ions. For some "metal-drug" coordination particles with unsuitable bond energy or irregular NP morphology, host ligands, such as PEG, oligochitosan, and Pluronic F127, were introduced to endow the particles with appropriate size and $\mathrm{pH}$ sensitivity. For example, mitoxantrone (MX)-Cu NPs did not release $\mathrm{MX}$, even in a highly acidic medium, because of their strong coordination bond. In this case, PEG was introduced as the host molecule to weaken the coordination bond, which was achieved based on the weak coordination binding site provided by the EO moiety of PEG. Although the article did not provide a specific drug-loading content, such values were obviously high in these nanomedicines. With this strategy, Moustaoui et al reported another ICP I-type high drug-loading nanomedicine, PEG-Au(III)-Dox, in a recent work. ${ }^{165}$ In this nanomedicine, Dox molecules and dicarboxylic PEG molecules were chelated with $\mathrm{Au}(\mathrm{III})$ ions from tetrachloroauric acid $\left(\mathrm{HAuC}_{14}\right)$. It was demonstrated that nanomedicine depolymerization and effective Dox release were achieved at $\mathrm{pH} 4$, with stability attained at a diameter close to $20 \mathrm{~nm}$ in physiological $\mathrm{pH}$. The drug-loading efficiency of Dox in this nanomedicine was up to $85 \%$.

The following issues are worth noting. This strategy is only applied to drugs possessing complexation ability, such as carboxylates and phosphonates, including daunorubicin

\section{Strategy A: ICP I-type nanomedicine}

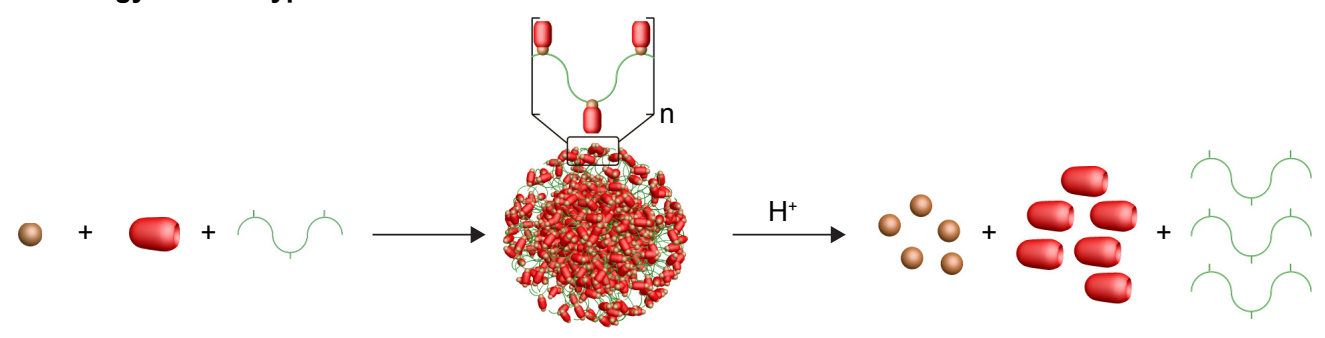

Strategy B: IICP II-type nanomedicine

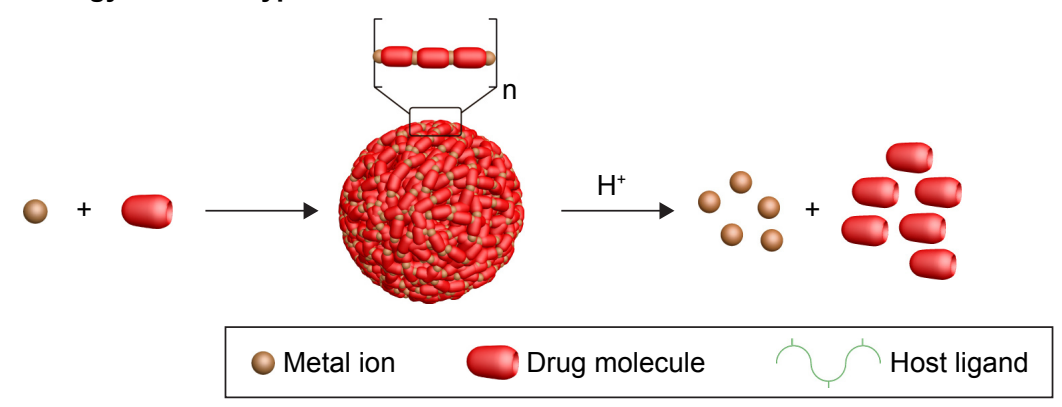

Figure 7 Formation of ICP I-type nanomedicine and ICP II-type nanomedicine and their pH-responsive release. Abbreviation: ICP, infinite coordination polymer. 
hydrochloride, Dox hydrochloride, MX, alizarin red, 1,10phenanthroline, cis-platinum, 1,4-bis-([2-\{dimethylamino$\mathrm{N}$-oxide \}ethyl]amino)5,8-dihydroxyanthracene-9,10-dione (AQ4N), and gossypol. ${ }^{165-167}$ The particle size and $\mathrm{pH}-$ responsive point of nanomedicines are dependent on the complex combinations of host ligands, drug molecules, and center metal ions. Computational design and combinatorial chemistry can be utilized as primary screening to equip ICP I-type nanomedicines with ideal properties. More studies on cell and animal levels are needed to confirm the outstanding antitumor effects of ICP I-type nanomedicines.

\section{Carrier-free nanomedicines}

With the previously mentioned strategies, a significant number of high drug-loading nanomedicines have been developed (Tables 1 and 2). However, an intrinsic problem in these nanomedicines is that their degradation and excipient-excretion rates remain undetermined. ${ }^{168}$ To circumvent this concern, carrier-free nanomedicines with no excipient were developed, such as traditional DNCs, DDC micelles, MBioFs, and ICP II-type nanomedicines. All these types of nanomedicines often have drug-loading contents higher than $80 \mathrm{wt} \%$. These strategies are summarized in Table 3. Obviously, these strategies were applied for nanomedicine loading with drugs that are stable in the circulatory system, which are similar to those shown in Table 2.

\section{Drug nanocrystals}

DNCs are a conventional viable strategy to develop hydrophobic drug nanomedicines with the advantages of general applicability and simplicity. Basically, such nanomedicines consist of DNCs dispersed in liquid medium, and are stabilized by surface-active agents, such as the poloxamer family, ${ }^{169-173}$ Tween, ${ }^{174-176}$ and polymers. ${ }^{177-180}$ For oral administration, the high surface:volume ratios of DNCs significantly increase dissolution velocity, thereby leading to an improvement in the gastrointestinal tract absorption based on the Noyes-Whitney equation. ${ }^{181}$ For intravenous administration, the smallness of this nanomedicine enables it to enter blood circulation and achieve targeted delivery through further surface modification. In general, the conversion of a medical technology converted into a market product takes several decades, but a DNC-type nanomedicine (also called nanosuspensions) only needs several years. ${ }^{182}$ The first DNC product for oral application (named Rapamune ${ }^{\circledR}$ ) was successfully introduced to the market by Wyeth in 2000 . Moreover, the first DNC product for intravenous application (named Abraxane ${ }^{\circledR}$ ) was placed on the market by American Pharmaceutical Partners. Currently, several products are undergoing clinical trials and will be on the market in the near future. DNC-fabrication techniques are classified as either "top-down" or "bottom-up" methods, based on the size-change process. ${ }^{183}$ The top-down method starts from large crystals to small NCs in a step-by-step manner during a high-energy process, such as pearl milling and high-pressure homogenization. ${ }^{182,184-186}$ The bottom-up method involves procedures that start from molecules to NCs, such as solvent exchange, ${ }^{21,187-189}$ high-gravity-control precipitation, ${ }^{188,190,191}$ evaporative precipitation, ${ }^{192}$ rapid expansion of supercritical solution, ${ }^{193}$ and supercritical antisolvent methods. ${ }^{194}$ DNCs prepared via bottom-up methods need less energy and are smaller compared with those prepared through top-down methods. Solvent exchange is the simplest, commonest, and most cost-effective method used in laboratory experiments. This method can produce both crystalline and amorphous forms of DNCs. DNCs smaller than $200 \mathrm{~nm}$ can be administered intravenously with $100 \%$ bioavailability and achieve multifunctionality. ${ }^{195,196} \mathrm{Li}$ et al developed differently shaped 10-hydroxy-CPT (HCPT) NCs, nanospheres (NSs), and nanorods using solvent exchange and further surface modification. ${ }^{197}$ Polymaleic anhydride-alt-1-octadecenePEG (C18PMH-PEG) was chosen as a stabilizer, which was

Table 3 Overview of three strategies of carrier-free nanomedicines

\begin{tabular}{|c|c|c|c|c|c|}
\hline Strategy & Structure diagram & Main drug-loading mechanism & Application range & $\begin{array}{l}\text { Drug-loading } \\
\text { content }\end{array}$ & References \\
\hline Drug nanocrystals & & Crystallization & $\begin{array}{l}\text { Hydrophobic drugs } \\
\text { mostly }\end{array}$ & $\leq 93.3$ wt $\%$ & $\begin{array}{l}21,169-180 \\
182-200\end{array}$ \\
\hline $\begin{array}{l}\text { Amphiphilic drug- } \\
\text { drug conjugate }\end{array}$ & & Covalent bond & $\begin{array}{l}\text { Hydrophobic- } \\
\text { hydrophilic drug pairs }\end{array}$ & $\leq 100 w t \%$ & $20 \mathrm{I}-204$ \\
\hline CP nanoparticles & $\begin{array}{l}\text { MBioFs } \\
\text { ICP II-type }\end{array}$ & Coordinate bond & $\begin{array}{l}\text { Drugs with complexing } \\
\text { ability (both } \\
\text { hydrophobic drugs and } \\
\text { hydrophilic drugs) }\end{array}$ & $\begin{array}{l}\leq 75 w t \% \\
\leq 79.1 \text { wt } \%\end{array}$ & $\begin{array}{l}207 \\
209-213\end{array}$ \\
\hline
\end{tabular}

Abbreviations: CP, coordination polymer; MBioFs, metal-biomolecule frameworks; ICP, infinite coordination polymer; wt, weight. 
introduced on the surfaces of DNCs through noncovalent hydrophobic interaction. The surface PEGylation on HCPT NCs served as a steric repulsion-hydration molecular layer to reduce electrostatic and hydrophobic interactions with biomolecules, endowing them with excellent long-term stability at high salt concentrations and extreme $\mathrm{pH} .{ }^{198}$ The drug-loading contents of PEGylated NSs and nanorods were as high as $91.9 \mathrm{wt} \%$ and $93.3 \mathrm{wt} \%$, respectively. In other research, HCPT NCs with targeted delivery ability were prepared using solvent exchange, followed by surface functionalization with C18PMH-PEG-FA. ${ }^{199}$ This nanomedicine benefited from the high selectivity of FA to folate receptor-positive cancer cells, resulting in enhanced drug efficacy. The drug-loading content in this nanomedicine was approximately $78 \%$. DNCs can also be used for the fabrication of an all-in-one processing system for cancer diagnosis and treatment. Zhou et al developed carrier-free multifunctional multi-DNCs (MDNCs) that consisted of methotrexate (Mtx), HCPT, Ptx, and the amphiphilic polymer stabilizer C18PMH-PEG (Figure 8). ${ }^{200}$ The MDNCs were prepared through solvent exchange, and the PEG layer was added on the surface via hydrophobic interaction. In vitro studies demonstrated that the MDNCs showed synergistic effects and improved tolerance. Given the minute amount of red fluorescent dye (TBPT, synthesized by themselves), the MDNCs exhibited high contrast during in vivo imaging. The drug-loading contents of Mtx, HCPT, and Ptx were $24.3 \mathrm{wt} \%$, $49.1 \mathrm{wt} \%$, and $26.6 \mathrm{wt} \%$, respectively.

DNCs are a traditional assembly technology utilized in the fabrication of high drug-loading nanomedicine. Considerable developments have been made in NC-assembly technology over the last decade. However, certain limitations still exist: 1) both top-down and bottom-up methods apply only to the fabrication of hydrophobic high drug-loading nanomedicines, and thus the range of application is limited by the

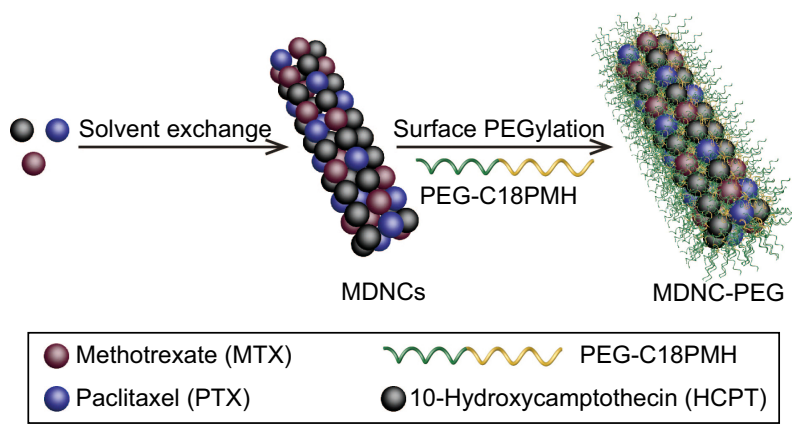

Figure 8 Preparation and functionalization of MDNCs. Abbreviations: MDNC, multidrug nanocrystal; PEG, polyethylene glycol; $\mathrm{PMH}$, polymaleic anhydride-alt-I-octadecene. requirement of drug solubility; 2) the problem of removing residual organic solvent cannot be neglected for industrial production; and 3) most studies on crystal nanomedicine have focused on the solubility problem of hydrophobic drugs, and few have involved sustained release, targeting problems, and cell uptake of DNCs. Therefore, research on surface modification and cyclic behavior of nanomedicine crystal in vivo represents an important direction for further DNC development.

\section{Amphiphilic drug-drug conjugates}

ADDCs are a class of special PDCs in which the hydrophilic and hydrophobic parts are represented by hydrophilic and hydrophobic drugs, respectively. This class of dual-drugloaded nanomedicines has the advantages of ultrahigh drugloading content and synergistic combination chemotherapy because of its inherent nature. This strategy, which was first proposed by Huang et al, ${ }^{201}$ is considered an excellent candidate for the fabrication of dual-drug synergistic therapy nanomedicines with high and fixed drug loading. Two methods are proposed under this strategy. The first is the "natural method," which is applied to drug pairs when one drug has a carboxyl group and the other an activated hydroxyl group. The second is the "modified method," which is applied to any modifiable AD pairs using a linker compound. All these nanomedicines have sizes suitable for intravenous administration. The total drug-loading content is approximately $100 \mathrm{wt} \%$.

For the natural method, a dual-drug-loaded nanomedicine was synthesized from a hydrophilic anticancer drug, irinotecan (Ir), and a hydrophobic anticancer drug, chlorambucil (Cb), via a hydrolyzable ester linkage by Huang et al. ${ }^{201}$ The ester linkage was formed from the hydroxyl of Ir molecules and carboxyl of $\mathrm{Cb}$ molecules through direct esterification using dicyclohexylcarbodiimide/4-dimethylamino-pyridine without any addition (Figure 9A). The amphiphilic Ir-Cb conjugates self-assembled into micelles in aqueous solution with average size of approximately $75.7 \mathrm{~nm}$. After cell uptake of nanomedicine, the ester linkages were hydrolyzed by the existing esterase and low $\mathrm{pH}$ in endosomes, causing the drug molecules to be effectively released. In vitro and in vivo antitumor experiments demonstrated that this nanomedicine exhibited high anticancer activity and could circumvent the multidrug resistance of tumor cells in chemotherapy. The same method was also used to fabricate fluorodeoxyuridine-bendamustine (FUDR-BdM) and Ir-BdM conjugates by Huang et al. ${ }^{202,203}$

The range of application of this strategy is widely extended with the use of the modified method. For example, 


\section{A Natural method}

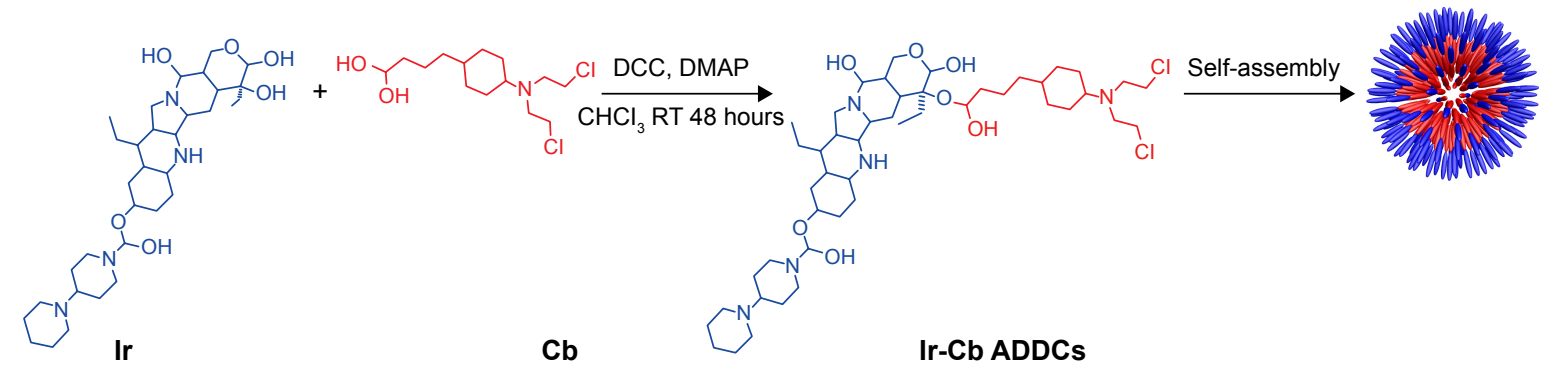

\section{B Modified method}
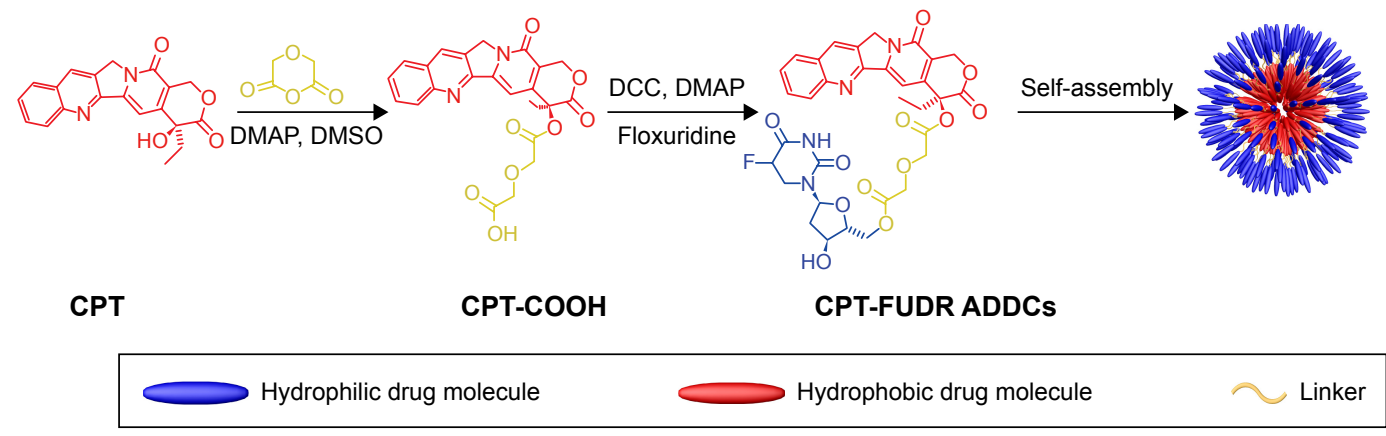

Figure $9 \mathrm{Ir}-\mathrm{Cb}$ ADDC following natural method (A) and CPT-FUDR ADDCs following modified method (B).

Abbreviations: Ir, irinotecan; Cb, chlorambucil; ADDCs, amphiphilic drug-drug conjugates; CPT, camptothecin; FUDR, fluorodeoxyuridine; DCC, dicyclohexylcarbodiimide; DMAP, dimethylaminopyridine; RT, room temperature; DMSO, dimethyl sulfoxide.

in a recent work of $\mathrm{Hu}$ et $\mathrm{al},{ }^{204}$ a dual-drug-loaded nanomedicine, CPT-FUDR conjugates, was synthesized through two-step esterification of hydrophobic CPT and hydrophilic FUDR using a linker compound. As illustrated in Figure 9B, the first step was the introduction of a carboxylic group onto the CPT molecule through esterification of CPT and diglycolic anhydride. Subsequently, the esterification reaction of CPT-COOH and FUDR was carried out, and the amphiphilic CPT-FUDR conjugate linked by a hydrolyzable ester was formed. The resultant amphiphilic conjugate self-assembled into nanomicelles with hydrodynamic size of $36.4 \mathrm{~nm}$. In vitro studies demonstrated that CPT-FUDR conjugates exhibited synergistic anticancer efficacy and similar intracellular behavior to DDC nanomedicines prepared via the natural method.

The following findings are noted. ADDCs are a kind of high drug-loading nanomedicine with narrow applicable range. This requires one of the drugs to be hydrophilic and the other to be hydrophobic, and these two drugs should satisfy a specific structure simultaneously. Few drug pairs possess these conditions while having a synergistic effect at the same time. Although some ADDC pairs have been reported to possess good anticancer efficacy, the influence of the structural modification of drug molecules on anticancer efficacy and pharmacokinetics is impossible to predict, especially the influence of the structural transformation of drug molecules caused by linker compound in the modified method. Further surface modification is difficult, due to the micelle-type structure of ADDC nanomedicines. Therefore, additional research should be concentrated on the surface modification of drug molecules and pharmacokinetics in the future.

\section{Coordination polymer NPs}

In this section, we focus on MBioFs and ICP II-type high drug-loading nanomedicines, in which the drug molecule acts as the only ligand coordinating with the central metal atom without any other vehicle components. Similar to ICP I-type nanomedicines, MBioFs and ICP II-type strategies are only applicable to those drugs with complexing ability.

\section{MBioFs}

MBioFs are defined as MOFs constructed from biomolecules that serve as organic ligands, such as amino acids, peptides, proteins, nucleobases, saccharides, and drug molecules (Figure 4). ${ }^{205}$ MBioFs display more advantages in the fabrication of high drug-loading nanomedicines than MOFs: 1) MBioFs avoid the structural requirements of MOFs, such as pore size and volume; 2) drug release is achieved through nanostructure biodegradation, without any side effects, 
because no inert material linkers are used; and 3) drug molecules often have many different metal-binding sites, which leads to multiple possible coordination modes and adjustable physical and chemical properties. ${ }^{206}$ For example, Miller et al developed a small-pore iron (II/III) nicotinate Bio-MIL1, which consists of nicotinic acid (pyridine-3-carboxylic acid, also called niacin or vitamin $\mathrm{B}_{3}$ ) and nontoxic iron. ${ }^{207}$ The structure of Bio-MIL1 comprises a three-dimensional connected framework built from trimeric $\mathrm{Fe}_{3} \mathrm{~N}_{3} \mathrm{O}_{13}$ units linked together via nicotinate molecules. These nanomedicines have a drug-loading content as high as $75 \mathrm{wt} \%$, and are rapidly degraded to achieve nicotinic acid release under physiological conditions. To date, MBioF nanomedicines have not been fully explored. Only some examples have been reported, and almost no studies on cell and animal levels can be searched. A possible explanation is that the stability of some MBioFs in aqueous and in vivo environments is not yet known. ${ }^{120,205,208}$ As such, further in vitro and in vivo studies should be conducted so that MBioFs have wide application prospects in the biomedical field.

\section{ICP II-type nanomedicines}

ICP II-type nanomedicines are ICPs prepared directly from drug molecules and metal atoms (Figure 7). ICP II-type nanomedicines display the same advantages as ICP I-type nanomedicines, and have higher drug-loading content. ICP II-type nanomedicines can be formed from a number of self-assembly processes. ${ }^{209-211}$ Solvothermal synthesis is the most straightforward method, and consists of metal and ligand molecules heated in a solvent, which can lead to the formation of amorphous or crystalline products. ICP II-type can also be synthesized using reverse microemulsion (water in oil), in which the reactants are suspended in surfactant-stabilized aqueous droplets in the organic phase and the droplets behave as nanoreactors, facilitating ICP assembly. Finally, ICPs can be formed via rapid precipitation that involves precipitating a solution of reactants with a solvent, which usually results in amorphous particle formation. For instance, Rieter et al fabricated an ICP II-type nanomedicine from $\mathrm{Tb}(\mathrm{III})$ ions and $c, c, t-\left(\mathrm{PtCl}_{2}\left[\mathrm{NH}_{3}\right]_{2}\left[\mathrm{O}_{2} \mathrm{CCH}_{2} \mathrm{CH}_{2} \mathrm{CO}_{2} \mathrm{H}\right]_{2}\right)$ (disuccinatocisplatin, $[\mathrm{DSCP}]$ ) via rapid precipitation (Figure 10). ${ }^{212}$ The Tb(III)-DSCP ICPs displayed a size of $58.3 \pm 11.3 \mathrm{~nm}$ in diameter using dynamic light scattering. The drug-loading content of DSCP was $36 \mathrm{wt} \%$, which was determined through thermogravimetric analysis. These ICP particles were easily functionalized with a variety of silyl-derived molecules and further grafted to silyl-derived $c$ (RGDfK), which is a small cyclic peptide sequence that is frequently observed in many angiogenic cancers, on the surface to achieve targeted delivery. Huxford et al synthesized serious ICP II-type Mtx nanomedicines via reverse microemulsion. ${ }^{213}$ Different metal ions, such as $\mathrm{Zn}^{2+}, \mathrm{Zr}^{4+}$, and $\mathrm{Gd}^{3+}$, with different coordination numbers were chosen to be coordinated with Mtx. The ICPs were further stabilized and modified using dioleoyl trimethylammonium propane/dioleoyl-L- $\alpha$ phosphatidylethanolamine-anisamide. These nanomedicines were spherical in appearance with diameters between 40 and $100 \mathrm{~nm}$ via transmission electron microscopy. Thermogravimetric analysis revealed that the drug-loading content of Mtx reached $79.1 \mathrm{wt} \%$.

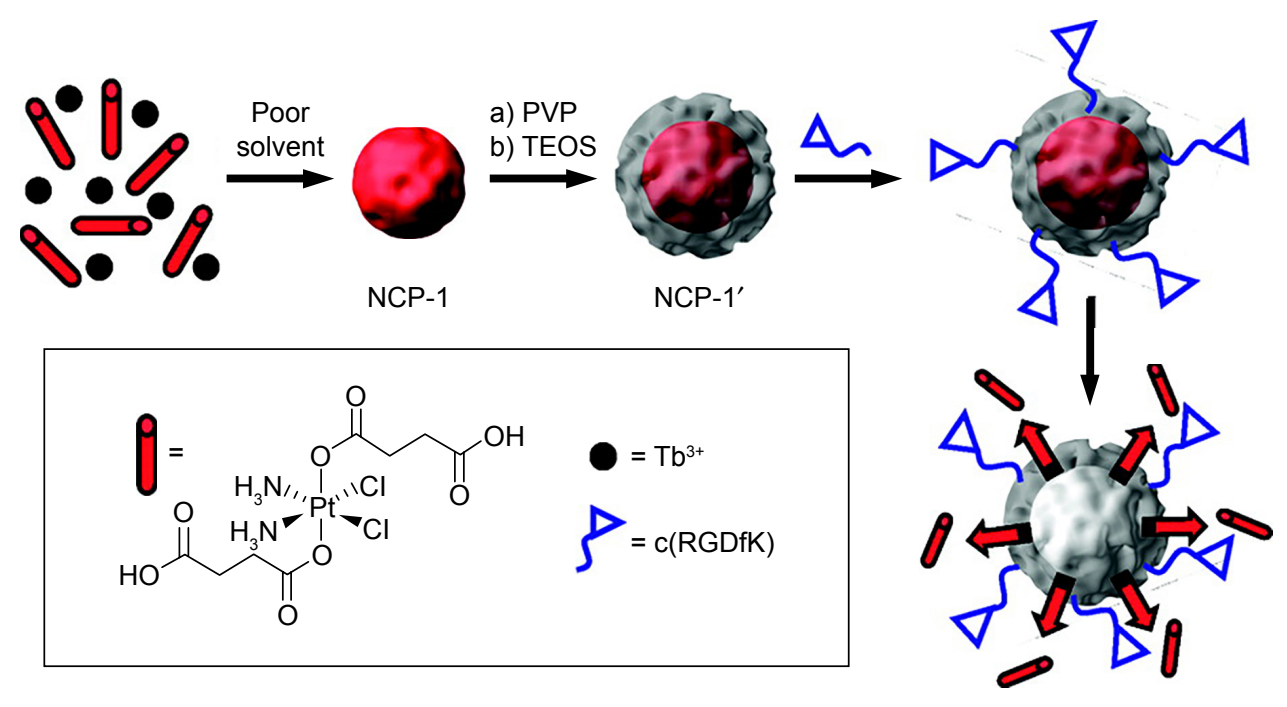

Figure 10 Synthesis and functionalization of Tb(III)-DSCP ICPs.

Notes: Reprinted (in part) with permission from Rieter WJ, Pott KM, Taylor KM, Lin WB. Nanoscale coordination polymers for platinum-based anticancer drug delivery. Journal of the American Chemical Society. 2008; 130(35): I I584-I I585. Copyright (C) 2008 American Chemical Society. ${ }^{212}$

Abbreviations: DSCP, disuccinatocisplatin; ICPs, infinite coordination polymers; NCP, nano-coordination polymer; PVP, polyvinylpyrrolidone; TEOS, tetraethyl orthosilicate. 
MBioF and ICP II-type strategies are not broad-spectrum techniques, due to the requirement of drug-complexing ability, similar to ICP I-type strategy. In addition, controlling the size of these nanomedicines is not easy, because of the absence of host ligands. Fortunately, molecular simulations are possible, because of the one-component feature and ultrahigh drug-loading content and efficiency of these nanomedicines. The application of computational design and combinatorial chemistry will allow the efficient design of MBioF and ICP II-type high drug-loading nanomedicines.

\section{Nanomedicines following niche and complex strategies}

Some niche and complex strategies, such as aqueous noncovalent assembly and multiple assemblies, are used for the fabrication of specific multidrug-loaded high drug-loading nanomedicines (Table 4). For aqueous noncovalent assembly, the selected drugs should possess opposite static electricity, $\pi-\pi$ stacking, and hydrophobic interactions. The biggest difference between solvent exchange for DNC fabrication and noncovalent assembly is that the former is applied for the fabrication of hydrophobic drug-loaded nanomedicines, whereas the latter is utilized for the fabrication of hydrophilic (including water-soluble drugs under certain conditions) drug-loaded nanomedicines. In this strategy, no organic solvent is used in the fabrication process. The molar ratio of multiple drugs is tailorable within a certain range, and the total drug-loading content for nanomedicines is $100 \mathrm{wt} \%$. Zhang et al developed a carrier-free, chemophotodynamic dual-drug-loaded nanomedicine prepared from a chemotherapeutic agent (Dox) and a photosensitizer (chlorine $\left.\mathrm{e}_{6}\left[\mathrm{Ce}_{6}\right]\right) .{ }^{14}$ Depending on electrostatic, $\pi-\pi$ stacking, and hydrophobic interactions, drug molecules self-assembled into well-defined NSs with an average size of $70 \mathrm{~nm}$ in a basic aqueous solution ( $\mathrm{pH}$ 12). Total drug-loading content was $100 \mathrm{wt} \%$, and drug-loading efficiency of $\mathrm{Ce}_{6}$ and Dox were $95 \%$ and $99 \%$, respectively. Further experiments on BALB/c nude mice with xenografted MCF7 tumors demonstrated that this carrier-free, chemophotodynamic dual-drug-loaded nanomedicine was an effective combinational therapeutic modality. Similarly, a novel high drug-loaded nanomedicine is currently being studied by our group.

For multiple assemblies, the selected drug-carrier pairs should possess appropriately matched physical and chemical properties. Notably, this strategy is a comprehensive strategy for the fabrication of multidrug-loaded nanomedicine. Recently, our group reported a mulberry-like dual-drugloaded nanomedicine following this strategy. ${ }^{214}$ First, two perfectly matched drug-carrier pairs, apogossypolonecationic amphiphilic starch (ApoG2-CSaSt) and Dox-HA, self-assembled to form two seeds, namely, ApoG2-CSaSt micelles and Dox-HA NSs (DHA NSs), respectively. These two seeds further self-assembled to form NPs (MLDC NCs) with a mulberry-like shape and dynamic size of $83.1 \pm 6.6 \mathrm{~nm}$. The first self-assembly occurred based on the hydrophobic interaction in the ApoG2-CSaSt pair and the electrostatic absorption in the DHA pair. The subsequent self-assembly occurred based on the electrostatic absorption between CSaSt and HA caused by the designed positive charge of CSaSt and the natural negative charge of HA. DHA NSs located on the surface of MLDC NCs functioned as a targeting agent at the same time. The drug-loading contents of ApoG2 and Dox in MLDC NCs were $13.3 \% \pm 1.2 \%$ and $13.1 \% \pm 3.7 \%$, respectively, and these values were adjustable to a certain extent. For the in vivo tumor-suppression test, the injection dosages of Dox and ApoG2 were both $2 \mathrm{mg} / \mathrm{kg}$, which was only a fifth of the normal dosages in the mouse test, and resulted in enhanced antitumor effects. This result suggested that high drug-loading nanomedicines can effectively realize multidrug synergy and have obvious antitumor advantages compared with low drug-loading nanomedicines.

Deng et al developed an anticancer drug and siRNAloaded nanomedicine following a similar strategy. First, a Dox-loaded negatively charged phospholipid liposome was developed. ${ }^{215}$ Consequently, a siRNA-loaded film was generated through alternate deposition of positively charged poly-L-arginine and negatively charged siRNA atop the Dox-loaded liposome. Finally, the NP surface was coated with a layer of HA to achieve targeted delivery. The loading efficiency and content of Dox in the nanomedicine were

Table 4 Overview of two strategies used for minority-specific nanomedicines

\begin{tabular}{|c|c|c|c|c|c|}
\hline Strategy & $\begin{array}{l}\text { Structure } \\
\text { diagram }\end{array}$ & Main drug-loading mechanism & Application range & $\begin{array}{l}\text { Drug-loading } \\
\text { content }\end{array}$ & References \\
\hline $\begin{array}{l}\text { Noncovalent } \\
\text { assembly }\end{array}$ & & $\begin{array}{l}\text { Noncovalent electrostatic and/or } \pi-\pi \\
\text { stacking and/or hydrogen bond and/or } \\
\text { hydrophobic interaction in drug pairs }\end{array}$ & $\begin{array}{l}\text { Water-soluble drugs (both hydrophilic } \\
\text { drugs and water-soluble hydrophobic } \\
\text { drugs under certain conditions) }\end{array}$ & 100 wt $\%$ & 14 \\
\hline $\begin{array}{l}\text { Multiple } \\
\text { assembly }\end{array}$ & & $\begin{array}{l}\text { Noncovalent electrostatic and hydrophobic } \\
\text { interaction in drug-carrier pairs }\end{array}$ & $\begin{array}{l}\text { Specific drug pairs (both hydrophobic } \\
\text { drugs, hydrophilic drugs and gene drugs) }\end{array}$ & 26.4 wt $\%$ & 214,215 \\
\hline
\end{tabular}

Abbreviation: wt, weight. 
$97 \mathrm{wt} \%$ and $5.5 \mathrm{wt} \%$, respectively. In addition, the poly-Larginine/siRNA layer-by-layer film loaded approximately 3,500 siRNA molecules per NP per layer. Niche and complex strategies are usually applicable for particular drugs or drug pairs, and their implementation schemes are unsuitable for other nanomedicines. However, the design philosophy, which ingeniously takes advantage of the special physicochemical property of drugs or drug pairs, is worth learning from.

\section{Conclusion and prospects}

In the past 30 years, the development of nanocarrier-based platform technologies has led to significant progress in nanomedicine fabrication and applications. However, most of the existing nanomedicines have low drug-loading content (generally lower than $10 \%$ ), causing extra system toxicity and burden on patients to excrete carrier materials. Therefore, it is difficult for most of the carrier-based nanomedicines to get FDA approval, which limits their applications in the clinic. With this in mind, emergence and fabrication of high drug-loading nanomedicines may not provide the final answer, but present a promising alternative approach to solve this problem, because of the reduced or avoided use of carrier materials.

The three classes of high drug-loading nanomedicines, which can either reduce or avoid the use of carrier materials, are applied to the fabrication of high drug-loading nanomedicines with different drug properties. In addition to common advantages of nanomedicines, some high drug-loadingnanomedicines possess inherent advantages, benefiting from their structure and ultrahigh drug-loading content and efficiency, such as stimulant responsibility, multidrug combined therapy, computational design, and combinatorial chemistry properties. Despite all these benefits, the therapeutic effect of current high drug-loading nanomedicines is not so satisfactory. Furthermore, several theoretical and actual problems remain unsolved. Demonstrating the better in vivo antitumor effect of high drug-loading nanomedicines than low drug-loading nanomedicines is significant. However, most existing high drug-loading nanomedicine studies have focused on design and fabrication and lacked comparison of the antitumor effect at the animal level. As such, these studies failed to demonstrate the complete advantages of high drug-loading nanomedicines. Understanding the differences between the antitumor mechanisms of high drug-loading and low drug-loading nanomedicines is important to improve the design of subsequent high drug-loading nanomedicines. However, existing reports on high drug-loading nanomedicines have mostly focused on nanomedicine design, and almost no research has been conducted on the internalization mechanism, intracellular release, and subcellular level actions. Owing to long conversion times, safety concerns, and associated socioeconomic uncertainties, most concepts investigated are at the laboratory stage, and a few have entered routine clinical application, such as Rapamune and Abraxane, which we discussed in this paper. Despite this, it irresistible that more high drug-loading nanomedicines will be transitioned into clinics in the future. ${ }^{216}$

Meanwhile, the following issues are worth noting. For some specific drugs, such as gene drugs that are unstable in the circulatory system and brain-targeting drugs that need to cross the blood-brain barrier, carrier materials are essential for the realization of their function. For some carrier materials with function, such as Pluronic block copolymers, biological response modifiers affecting cell-membrane microviscosity and ATPase activity of drug-efflux transporters, the use of carrier materials will enhance the therapeutic effect. ${ }^{217}$ For most of the high drug-loading nanomedicines, it is hard to realize in vivo controlled release, such as ultrasoundcontrolled release, magnetism-controlled release, and microwave-controlled release. For nanomedicines with drugloading content higher than $50 \%$, sustained-release effects are far below expected, and there are fewer pharmacokinetic studies in this category of articles. For nanomedicines with drug-loading content higher than $90 \%$, it is usually hard to achieve surface modification, so further study is needed on the action of those high drug-loading nanomedicines in the complicated physiological environment and highly dynamic and heterogeneous tumor sites. Clearly, the high drug-loading property serves therapeutic effect and function purposes.

Over the past few years, the number of FDA-approved drugs, including protein drugs, oligonucleotide drugs, and small-molecule inhibitors, has increased, such as lixisenatide, ${ }^{218}$ defibrotide sodium, ${ }^{219}$ and rucaparib. ${ }^{220}$ Although these drugs show excellent performance against certain diseases, it cannot be ignored that their inherent drawbacks, such as poor water solubility and unstable properties in the circulatory system, lead to unsatisfactory absorption and frequent injection for patients. A promising approach to overcome these drawbacks is loading them into nanomedicine. Even though much time and high costs are required to develop a new nanomedicine, we still believe that there will be more nanomedicines approved by the FDA in the future. We hope that this review will attract more attention from researchers in this field, and expect that high drug-loading nanomedicines with still-better properties will be prepared by developing novel carrier materials, exploring new fabrication strategies and modification methods and perfecting theoretical research at the cell and animal level. We also believe 
that high drug-loading nanomedicine-delivery systems will be gradually improved through the joint efforts of chemists, biologists, material specialists, and cancer and pharmaceutical researchers, and will occupy an important position in the field of drug-delivery systems in the future.

\section{Acknowledgment}

This work was sponsored in part by the National Natural Science Foundation of China (81271686, 81228011, and 81471771 ) and grants from the National Key Research and Development Program (2016YFC0100701).

\section{Disclosure}

The authors report no conflicts of interest in this work.

\section{References}

1. Kawabata Y, Wada K, Nakatani M, Yamada S, Onoue S. Formulation design for poorly water-soluble drugs based on biopharmaceutics classification system: basic approaches and practical applications. Int J Pharm. 2011;420(1):1-10.

2. Liggins RT, Burt HM. Polyether-polyester diblock copolymers for the preparation of paclitaxel loaded polymeric micelle formulations. Adv Drug Deliv Rev. 2002;54(2):191-202.

3. Du WT, Hong L, Yao TW, et al. Synthesis and evaluation of watersoluble docetaxel prodrugs-docetaxel esters of malic acid. Bioorg Med Chem. 2007;15(18):6323-6330.

4. Luke DR, Kasiske BL, Matzke GR, Awni WM, Keane WF. Effects of cyclosporine on the isolated perfused rat kidney. Transplantation. 1987;43(6):795-799.

5. Onetto N, Canetta R, Winograd B, et al. Overview of Taxol safety. J Natl Cancer Inst Monogr. 1993;(15):131-139.

6. Torchilin VP. Nanocarriers. Pharm Res. 2007;24(12):2333-2334.

7. Ferrari M. Cancer nanotechnology: opportunities and challenges. Nat Rev Cancer. 2005;5(3):161-171.

8. Wagner V, Dullaart A, Bock AK, Zweck A. The emerging nanomedicine landscape. Nat Biotechnol. 2006;24(10):1211-1217.

9. Allen TM, Cullis PR. Drug delivery systems: entering the mainstream. Science. 2004;303(5665):1818-1822.

10. Verma RK, Garg S. Current status of drug delivery technologies and future directions. Pharm Technol. 2001;25(2):1-14.

11. Wu J, Zhu YJ, Cao SW, Chen F. Hierachically [sic] nanostructured mesoporous spheres of calcium silicate hydrate: surfactant-free sonochemical synthesis and drug-delivery system with ultrahigh drugloading capacity. Adv Mater. 2010;22(6):749-753.

12. Liu KP, Zhang JJ, Cheng FF, Zheng TT, Wang CM, Zhu JJ. Green and facile synthesis of highly biocompatible graphene nanosheets and its application for cellular imaging and drug delivery. J Mater Chem. 2011;21(32):12034-12040.

13. Ye L, Letchford K, Heller M, et al. Synthesis and characterization of carboxylic acid conjugated, hydrophobically derivatized, hyperbranched polyglycerols as nanoparticulate drug carriers for cisplatin. Biomacromolecules. 2011;12(1):145-155.

14. Zhang RY, Xing RR, Jiao TF, et al. Carrier-free, chemophotodynamic dual nanodrugs via self-assembly for synergistic antitumor therapy. ACS Appl Mater Interfaces. 2016;8(21):13262-13269.

15. Trucillo $\mathrm{P}$, Campardelli R, Reverchon E. Supercritical $\mathrm{CO}_{2}$ assisted liposomes formation: optimization of the lipidic layer for an efficient hydrophilic drug loading. $\mathrm{JCO}_{2}$ Util. 2017;18:181-188.

16. Zhang W, Wang G, Falconer JR, et al. Strategies to maximize liposomal drug loading for a poorly water-soluble anticancer drug. Pharm Res. 2015;32(4):1451-1461.
17. Ribeiro CA, Castro CE, Albuquerque LJ, Batista CC, Giacomelli FC. Biodegradable nanoparticles as nanomedicines: are drug-loading content and release mechanism dictated by particle density? Colloid Polym Sci. Epub 2017 Jan 9.

18. Zheng SJ, Xie YQ, Li Y, et al. Development of high drug-loading nanomicelles targeting steroids to the brain. Int J Nanomedicine. 2014; 9:55-66.

19. Qin SY, Zhang AQ, Cheng SX, Rong L, Zhang XZ. Drug self-delivery systems for cancer therapy. Biomaterials. 2016;112:234-247.

20. Cai KM, He X, Song ZY, et al. Dimeric drug polymeric nanoparticles with exceptionally high drug loading and quantitative loading efficiency. J Am Chem Soc. 2015;137(10):3458-3461.

21. Zhang J, Li S, An FF, et al. Self-carried curcumin nanoparticles for in vitro and in vivo cancer therapy with real-time monitoring of drug release. Nanoscale. 2015;7(32):13503-13510.

22. Lokich JJ, Zipoli TE, Moore C, Sonneborn H, Paul S, Greene R. Doxorubicin/vinblastine and doxorubicin/cyclophosphamide combination chemotherapy by continuous infusion. Cancer. 1986;58(5):1020-1023.

23. Azad NS, Posadas EM, Kwitkowski VE, et al. Combination targeted therapy with sorafenib and bevacizumab results in enhanced toxicity and antitumor activity. J Clin Oncol. 2008;26(22):3709-3714.

24. Blank CU, Hooijkaas AI, Haanen JB, Schumacher TN. Combination of targeted therapy and immunotherapy in melanoma. Cancer Immunol Immunother. 2011;60(10):1359-1371.

25. Jiang HT, Wang TY, Wang LH, et al. Development of an amorphous mesoporous $\mathrm{TiO}_{2}$ nanosphere as a novel carrier for poorly water-soluble drugs: effect of different crystal forms of $\mathrm{TiO}_{2}$ carriers on drug loading and release behaviors. Microporous Mesoporous Mater. 2012;153(14): $124-130$.

26. Yu M, Xue Y, Ma PX, Mao C, Lei B. Intrinsic ultrahigh drug/miRNA loading capacity of biodegradable bioactive glass nanoparticles toward highly efficient pharmaceutical delivery. ACS Appl Mater Interfaces. 2017;9(10):8460-8470.

27. Vallet-Regi M, Rámila A, Real RP, Pérez-Pariente J. A new property of MCM-41: drug delivery system. Chem Mater. 2001;13(2):308-311.

28. Tarn D, Ashley CE, Xue M, Carnes EC, Zink JI, Brinker CJ. Mesoporous silica nanoparticle nanocarriers: biofunctionality and biocompatibility. Acc Chem Res. 2013;46(3):792-801.

29. Li X, Zhang LX, Dong XP, Liang J, Shi JL. Preparation of mesoporous calcium doped silica spheres with narrow size dispersion and their drug loading and degradation behavior. Microporous Mesoporous Mater. 2007;102(1-3):151-158.

30. Chen HT, Huh S, Lin VS. Fine tuning the functionalization of mesoporous silica. In: Regalbuto J, editor. Catalyst Preparation: Science and Engineering. New York: CRC Press; 2006:45-73.

31. Slowing II, Vivero-Escoto JL, Wu CW, Lin VS. Mesoporous silica nanoparticles as controlled release drug delivery and gene transfection carriers. Adv Drug Deliv Rev. 2008;60(11):1278-1288.

32. Burleigh MC, Dai S, Hagaman EW, Barnes CE, Xue ZL. Stepwise assembly of surface imprint sites on MCM-41 for selective metal ion separations. ACS Symp Ser Am Chem Soc. 2000;778:146-158.

33. Sun LZ, Wang Y, Zheng X, et al. Novel chitosan-functionalized spherical nanosilica matrix as an oral sustained drug delivery system for poorly water-soluble drug carvedilol. ACS Appl Mater Interfaces. 2013;5(1):103-113.

34. Eltohamy M, Seo JW, Hwang JY, Jang WC, Kim HW, Shin US. Ionic and thermo-switchable polymer-masked mesoporous silica drug-nanocarrier: high drug loading capacity at $10^{\circ} \mathrm{C}$ and fast drug release completion at $40^{\circ}$ C. Colloids Surf B Biointerfaces. 2016;144: 229-237.

35. Zhou GX, Zhang ZL, Chen B, et al. Synthesis of double-shelled hollow silica sphere with single-shelled hollow silica sphere and cetyltrimethyl ammonium bromide as dual templates. IET Micro Nano Lett. 2017; 12(2):133-135.

36. Eltohamy M, Shin US, Kim HW. Silica nanoparticles with enlarged nanopore size for the loading and release of biological proteins. Mater Lett. 2011;65(23):3570-3573. 
37. Zhu YF, Shi JL, Li YS, Chen HR, Dong XP. Hollow mesoporous spheres with cubic pore network as a potential carrier for drug storage and its in vitro release kinetics. J Mater Res. 2005;20(1):54-61.

38. Kresge CT, Leonowicz ME, Roth WJ, Vartuli JC, Beck JS. Ordered mesoporous molecular sieves synthesized by a liquid-crystal template mechanism. Nature. 1992;359(6397):710-712.

39. Zhu Y, Shi J, Shen W, et al. Stimuli-responsive controlled drug release from a hollow mesoporous silica sphere/polyelectrolyte multilayer core-shell structure. Angew Chem Int Ed Engl. 2005;44(32) 5083-5087.

40. Geng HJ, Zhao YT, Liu J, et al. Hollow mesoporous silica as a high drug loading carrier for regulation insoluble drug release. Int J Pharm. 2016;510(1):184-194.

41. Ebabe ER, Rahmani S, Lauret C, et al. Functionalized mesoporous silica nanoparticle with antioxidants as a new carrier that generates lower oxidative stress impact on cells. Mol Pharm. 2016;13(8):2647-2660.

42. Farsangi ZJ, Beitollahi A, Hatton B, et al. One-pot and controllable synthesis of carboxylic group functionalized hollow mesoporous silica nanospheres for efficient cisplatin delivery. RSC Adv. 2016;6(72): 67592-67598.

43. De Aza PN, Guitian F, De Aza S. Bioactivity of wollastonite ceramics: in vitro evaluation. Scr Metall Mater. 1994;31(8):1001-1005.

44. De Aza PN, Luklinska ZB, Martinez A, Anseau MR, Guitian F, De Aza S. Morphological and structural study of pseudowollastonite implants in bone. J Microsc. 2000;197(Pt 1):60-67.

45. Lin KL, Zhai WY, Ni SY, Chang J, Zeng Y, Qian WJ. Study of the mechanical property and in vitro biocompatibility of $\mathrm{CaSiO}_{3}$ ceramics. Ceram Int. 2005;31(2):323-326.

46. Wan XH, Chang CK, Mao DL, Jiang L, Li M. Preparation and in vitro bioactivities of calcium silicate nanophase materials. Mater Sci Eng C Biomim Supramol Syst. 2005;25(4):455-461.

47. Xue WC, Bandyopadhyay A, Bose S. Mesoporous calcium silicate for controlled release of bovine serum albumin protein. Acta Biomater. 2009;5(5):1686-1696.

48. Wang BX, Meng WY, Bi M, Ni YX, Cai Q, Wang JY. Uniform magnesium silicate hollow spheres as high drug-loading nanocarriers for cancer therapy with low systemic toxicity. Dalton Trans. 2013;42(24): 8918-8925.

49. Zhao YN, Trewyn BG, Slowing II, Lin VS. Mesoporous silica nanoparticle-based double drug delivery system for glucose-responsive controlled release of insulin and cyclic AMP. J Am Chem Soc. 2009; 131(24):8398-8400.

50. Lee S, Kim MS, Lee D, et al. The comparative immunotoxicity of mesoporous silica nanoparticles and colloidal silica nanoparticles in mice. Int J Nanomedicine. 2012;8:147-158.

51. Luo Z, Hu Y, Xin RH, et al. Surface functionalized mesoporous silica nanoparticles with natural proteins for reduced immunotoxicity. J Biomed Mater Res A. 2014;102(11):3781-3794.

52. Liu TL, Li LL, Fu CH, Liu HY, Chen D, Tang FQ. Pathological mechanisms of liver injury caused by continuous intraperitoneal injection of silica nanoparticles. Biomaterials. 2012;33(7):2399-2407.

53. Yamashita K, Yoshioka Y, Higashisaka K, et al. Silica and titanium dioxide nanoparticles cause pregnancy complications in mice. Nat Nanotechnol. 2011;6(5):321-328.

54. Yang XF, He CE, Li J, et al. Uptake of silica nanoparticles: neurotoxicity and Alzheimer-like pathology in human SK-N-SH and mouse neuro2a neuroblastoma cells. Toxicol Lett. 2014;229(1):240-249.

55. Tang L, Cheng JJ. Nonporous silica nanoparticles for nanomedicine application. Nano Today. 2013;8(3):290-312.

56. Kim TW, Chung PW, Slowing II, Tsunoda M, Yeung ES, Lin VS. Structurally ordered mesoporous carbon nanoparticles as transmembrane delivery vehicle in human cancer cells. Nano Lett. 2008;8(11): 3724-3727.

57. Zhang YZ, Zhi ZZ, Li X, Gao J, Song YL. Carboxylated mesoporous carbon microparticles as new approach to improve the oral bioavailability of poorly water-soluble carvedilol. Int J Pharm. 2013;454(1): 403-411.
58. Gu JL, Su SS, Li YS, He QJ, Shi JL. Hydrophilic mesoporous carbon nanoparticles as carriers for sustained release of hydrophobic anti-cancer drugs. Chem Commun (Camb). 2011;47(7):2101-2103.

59. Zhang YZ, Wang H, Gao CQ, Li X, Li LS. Highly ordered mesoporous carbon nanomatrix as a new approach to improve the oral absorption of the water-insoluble drug, simvastatin. Eur J Pharm Sci. 2013;49(5): $864-872$.

60. Niu X, Wan L, Hou Z, et al. Mesoporous carbon as a novel drug carrier of fenofibrate for enhancement of the dissolution and oral bioavailability. Int J Pharm. 2013;452(1-2):382-389.

61. Zhao P, Wang LH, Sun CS, et al. Uniform mesoporous carbon as a carrier for poorly water soluble drug and its cytotoxicity study. Eur J Pharm Biopharm. 2012;80(3):535-543.

62. Wang XF, Zhu XJ, Wang S, Pan YF, Tian Y. Direct synthesis of carbon microspheres under acidic conditions and fenofibrate release. Mater Lett. 2016;164:156-159.

63. Saha D, Spurri A, Chen JH, Hensley DK. Controlled release of alendronate from nitrogen-doped mesoporous carbon. Microporous Mesoporous Mater. 2016;229:8-13.

64. Zhang YZ, Wang H, Li CJ, et al. A novel three-dimensional largepore mesoporous carbon matrix as a potential nanovehicle for the fast release of the poorly water-soluble drug, celecoxib. Pharm Res. 2014; 31(4):1059-1070.

65. Hu B, Wang K, Wu LH, Yu SH, Antonietti M, Titirici MM. Engineering carbon materials from the hydrothermal carbonization process of biomass. Adv Mater. 2010;22(7):813-828.

66. Ryoo R, Joo SH, Jun S. Synthesis of highly ordered carbon molecular sieves via template-mediated structural transformation. JPhys Chem B. 1999;103(37):7743-7746.

67. Davis ME, Chen Z, Shin DM. Nanoparticle therapeutics: an emerging treatment modality for cancer. Nat Rev Drug Discov. 2008;7(9): 771-782.

68. Miao P, Tang YG, Han K, Wang BD. Facile synthesis of carbon nanodots from ethanol and their application in ferric(III) ion assay. J Mater Chem A Mater Energy Sustain. 2015;3(29):15068-15073.

69. Zhi X, Fang HL, Bao CC, et al. The immunotoxicity of graphene oxides and the effect of PVP-coating. Biomaterials. 2013;34(21):5254-5261.

70. Pondman KM, Sobik M, Nayak A, et al. Complement activation by carbon nanotubes and its influence on the phagocytosis and cytokine response by macrophages. Nanomedicine. 2014;10(6):1287-1299.

71. Mout R, Moyano DF, Rana S, Rotello VM. Surface functionalization of nanoparticles for nanomedicine. Chem Soc Rev. 2012;41(7): 2539-2544.

72. Jung SH, Jung SH, Seong H, Cho SH, Jeong KS, Shin BC. Polyethylene glycol-complexed cationic liposome for enhanced cellular uptake and anticancer activity. Int J Pharm. 2009;382(1-2):254-261.

73. Wang H, Li XG, Ma ZQ, et al. Hydrophilic mesoporous carbon nanospheres with high drug-loading efficiency for doxorubicin delivery and cancer therapy. Int J Nanomedicine. 2016;11:1793-1806.

74. Yang K, Zhang SA, Zhang GX, Sun XM, Lee ST, Liu ZA. Graphene in mice: ultrahigh in tumor uptake and efficient photothermal therapy. Nano Lett. 2010;10(9):3318-3323.

75. Zhang W, Guo ZY, Huang DQ, Liu ZM, Guo X, Zhong HQ. Synergistic effect of chemo-photothermal therapy using PEGylated graphene oxide. Biomaterials. 2011;32(33):8555-8561.

76. Wagner DS, Delk NA, Lukianova-Hleb EY, Hafner JH, FarachCarson MC, Lapotko DO. The in vivo performance of plasmonic nanobubbles as cell theranostic agents in zebrafish hosting prostate cancer xenografts. Biomaterials. 2010;31(29):7567-7574.

77. Burke A, Ding X, Singh R, et al. Long-term survival following a single treatment of kidney tumors with multiwalled carbon nanotubes and near-infrared radiation. Proc Nati Acad Sci U S A. 2009;106(31): 12897-12902.

78. Zhou L, Dong K, Chen ZW, Ren JS, Qu XG. Near-infrared absorbing mesoporous carbon nanoparticle as an intelligent drug carrier for dual-triggered synergistic cancer therapy. Carbon. 2015;82: $479-488$. 
79. Zhao Y, Lu Y, Hu Y, et al. Synthesis of superparamagnetic $\mathrm{CaCO}_{3}$ mesocrystals for multistage delivery in cancer therapy. Small. 2010; 6(21):2436-2442.

80. Shin JM, Anisur RM, Ko MK, Im GH, Lee JH, Lee IS. Hollow manganese oxide nanoparticles as multifunctional agents for magnetic resonance imaging and drug delivery. Angew Chem Int Ed Engl. 2009; 121(2):327-330

81. Li D, Tang J, Guo J, Wang SL, Chaudhary D, Wang CC. Hollow-core magnetic colloidal nanocrystal clusters with ligand-exchanged surface modification as delivery vehicles for targeted and stimuli-responsive drug release. Chemistry. 2012;18(51):16517-16524.

82. Deng YH, Wang CC, Shen XZ, et al. Preparation, characterization, and application of multistimuli-responsive microspheres with fluorescencelabeled magnetic cores and thermoresponsive shells. Chemistry. 2005;11(20):6006-6013.

83. Yoon TJ, Kim SJ, Kim GB, Yu KN, Cho MH, Lee JK. Multifunctional nanoparticles possessing a "magnetic motor effect" for drug or gene delivery. Angew Chem Int Ed Engl. 2005;117(7):1092-1095.

84. Kim J, Kim HS, Lee N, et al. Multifunctional uniform nanoparticles composed of a magnetite nanocrystal core and a mesoporous silica shell for magnetic resonance and fluorescence imaging and for drug delivery. Angew Chem Int Ed Engl. 2008;47(44):8438-8441.

85. Deng H, Li XL, Peng Q, Wang X, Chen JP, Li YD. Monodisperse magnetic single-crystal ferrite microspheres. Angew Chem Int Ed Engl. 2005;117(18):2842-2845.

86. Ge JP, Hu YX, Biasini M, Beyermann WP, Yin YD. Superparamagnetic magnetite colloidal nanocrystal clusters. Angew Chem Int Ed Engl. 2007;46(23):4342-4345.

87. Liu J, Sun ZK, Deng YH, et al. Highly water-dispersible biocompatible magnetite particles with low cytotoxicity stabilized by citrate groups. Angew Chem Int Ed Engl. 2009;121(32):5989-5993.

88. Luo B, Xu S, Luo A, et al. Mesoporous biocompatible and aciddegradable magnetic colloidal nanocrystal clusters with sustainable stability and high hydrophobic drug loading capacity. ACS Nano. 2011; 5(2):1428-1435.

89. Li D, Tang J, Wei C, et al. Doxorubicin-conjugated mesoporous magnetic colloidal nanocrystal clusters stabilized by polysaccharide as a smart anticancer drug vehicle. Small. 2012;8(17):2690-2697.

90. Cheng K, Peng S, Xu CJ, Sun SH. Porous hollow $\mathrm{Fe}_{3} \mathrm{O}_{4}$ nanoparticles for targeted delivery and controlled release of cisplatin. J Am Chem Soc. 2009;131(30):10637-10644.

91. Hu J, Chen M, Fang XS, Wu LW. Fabrication and application of inorganic hollow spheres. Chem Soc Rev. 2011;40(11):5472-5491.

92. Hu P, Yu LJ, Zuo AH, Guo CY, Yuan FL. Fabrication of monodisperse magnetite hollow spheres. J Phys Chem C Nanomater Interfaces. 2009; 113(3):900-906.

93. Liu SH, Xing RM, Lu F, Rana RK, Zhu JJ. One-pot template-free fabrication of hollow magnetite nanospheres and their application as potential drug carriers. J Phys Chem C Nanomater Interfaces. 2009; 113(50):21042-21047.

94. Luo B, Xu SA, Ma WF, et al. Fabrication of magnetite hollow porous nanocrystal shells as a drug carrier for paclitaxel. J Mater Chem. 2010; 20(34):7107-7113.

95. Drechsler A, Synytska A, Uhlmann P, Elmahdy MM, Stamm M, Kremer F. Interaction forces between microsized silica particles and weak polyelectrolyte brushes at varying $\mathrm{pH}$ and salt concentration. Langmuir. 2010;26(9):6400-6410.

96. Li HL, Eddaoudi M, O'Keeffe M, Yaghi OM. Design and synthesis of an exceptionally stable and highly porous metal-organic framework. Nature. 1999;402(6759):276-279.

97. Huxford RC, Rocca JD, Lin WB. Metal-organic frameworks as potential drug carriers. Curr Opin Chem Biol. 2010;14(2):262-268.

98. Wang F, Liu XG. Upconversion multicolor fine-tuning: visible to nearinfrared emission from lanthanide-doped $\mathrm{NaYF}_{4}$ nanoparticles. $\mathrm{J} \mathrm{Am}$ Chem Soc. 2008;130(17):5642-5643.

99. Lee J, Farha OK, Roberts J, Scheidt KA, Nguyen ST, Hupp JT. Metalorganic framework materials as catalysts. Chem Soc Rev. 2009;38(5): $1450-1459$.
100. Farrusseng D, Aguado S, Pinel C. Metal-organic frameworks: opportunities for catalysis. Angew Chem Int Ed Engl. 2009;48(41): 7502-7513.

101. Bell AT. The impact of nanoscience on heterogeneous catalysis. Science. 2003;299(5613):1688-1691.

102. Cao YW, Jin R, Mirkin CA. Nanoparticles with Raman spectroscopic fingerprints for DNA and RNA detection. Science. 2002; 297(5586):1536-1540.

103. Chen BL, Yang Y, Zapata F, Lin GN, Qian GD, Lobkovsky EB. Luminescent open metal sites within a metal-organic framework for sensing small molecules. Adv Mater. 2007;19(13):1693-1696.

104. Xiao B, Wheatley PS, Zhao XB, et al. High-capacity hydrogen and nitric oxide adsorption and storage in a metal-organic framework. J Am Chem Soc. 2007;129(5):1203-1209.

105. Mckinlay AC, Xiao B, Wragg DS, Wheatley PS, Megson IL, Morris RE. Exceptional behavior over the whole adsorption-storagedelivery cycle for NO in porous metal organic frameworks. $J$ Am Chem Soc. 2008;130(31):10440-10444.

106. Dietzel PD, Johnsen RE, Blom R, Fjellvåg H. Structural changes and coordinatively unsaturated metal atoms on dehydration of honeycomb analogous microporous metal-organic frameworks. Chemistry. 2008;14(8):2389-2397.

107. Zhao YJ, Zhang JL, Han BX, Song JL, Li JS, Wang Q. Metal-organic framework nanospheres with well-ordered mesopores synthesized in an ionic liquid/ $\mathrm{CO}_{2} /$ surfactant system. Angew Chem Int Ed Engl. 2011;50(3):636-639.

108. Horcajada P, Serre C, Vallet-Regí M, Sebban M, Taulelle F, Férey G. Metal-organic frameworks as efficient materials for drug delivery. Angew Chem Int Ed Engl. 2006;118(36):6120-6124.

109. Férey G, Serre C, Mellot-Draznieks C, et al. A hybrid solid with giant pores prepared by a combination of targeted chemistry, simulation, and powder diffraction. Angew Chem Int Ed Engl. 2004;116(46): 6456-6461.

110. Cai W, Chu CC, Liu G, Wang YX. Metal-organic framework-based nanomedicine platforms for drug delivery and molecular imaging. Small. 2015;11(37):4806-4822.

111. Wu M, Wang Q, Liu X, Liu J. Highly efficient loading of doxorubicin in Prussian blue nanocages for combined photothermal/ chemotherapy against hepatocellular carcinoma. RSC Adv. 2015; 5(39):30970-30980.

112. Zaidi R, Hadi SM. Strand scission in DNA by gossypol and Cu(II): role of $\mathrm{Cu}(\mathrm{I})$ and oxygen-free radicals. J Biochem Toxicol. 1992;7(4): 213-217.

113. Férey G, Mellotdraznieks C, Serre C, et al. A chromium terephthalatebased solid with unusually large pore volumes and surface area. Science. 2005;309(5743):2040-2042.

114. Babarao R, Jiang J. Unraveling the energetics and dynamics of ibuprofen in mesoporous metal-organic frameworks. J Phys Chem C Nanomater Interfaces. 2009;113(42):18287-18291.

115. Surblé S, Serre C, Mellot-Draznieks C, Millange F, Férey G. A new isoreticular class of metal-organic-frameworks with the MIL-88 topology. Chem Commun (Camb). 2006;(3):284-286.

116. Whitfield TR, Wang XQ, Liu LM, Jacobson AJ. Metal-organic frameworks based on iron oxide octahedral chains connected by benzenedicarboxylate dianions. Solid State Sci. 2005;7(9):1096-1103.

117. Horcajada P, Surblé S, Serre C, et al. Synthesis and catalytic properties of MIL-100(Fe), an iron(III) carboxylate with large pores. Chem Commun (Camb). 2007;(27):2820-2822.

118. Bauer S, Serre C, Devic T, et al. High-throughput assisted rationalization of the formation of metal organic frameworks in the iron(III) aminoterephthalate solvothermal system. Inorg Chem. 2008;47(17): 7568-7576.

119. Serre C, Millange F, Surblé S, Férey G. A route to the synthesis of trivalent transition-metal porous carboxylates with trimeric secondary building units. Angew Chem Int Ed Engl. 2004;43(46):6285-6289.

120. Horcajada P, Chalati T, Serre C, et al. Porous metal-organic-framework nanoscale carriers as a potential platform for drug delivery and imaging. Nat Mater. 2010;9(2):172-178. 
121. Molino NM, Wang SW. Caged protein nanoparticles for drug delivery. Curr Opin Biotechnol. 2014;28:75-82.

122. Ren D, Kratz F, Wang SW. Engineered drug-protein nanoparticle complexes for folate receptor targeting. Biochem Eng J. 2014;89: $33-41$.

123. Ren D, KratzF, Wang SW. Protein nanocapsules containing doxorubicin as a pH-responsive delivery system. Small. 2011;7(8):1051-1060.

124. Ren DM, Dalmau M, Randall A, Shindel MM, Baldi P, Wang SW. Biomimetic design of protein nanomaterials for hydrophobic molecular transport. Adv Funct Mater. 2012;22(15):3170-3180.

125. Choi K, Kim K, Kwon IC, Kim IS, Ahn HJ. Systemic delivery of siRNA by chimeric capsid protein: tumor targeting and RNAi activity in vivo. Mol Pharm. 2013;10(1):18-25.

126. Orlowski S, Garrigos M. Multiple recognition of various amphiphilic molecules by the multidrug resistance P-glycoprotein: molecular mechanisms and pharmacological consequences coming from functional interactions between various drugs. Anticancer Res. 1999;19(4B): 3109-3123.

127. Fang RH, Zhang L. Nanoparticle-based modulation of the immune system. Annu Rev Chem Biomol Eng. 2016;7(1):305-326.

128. Duro-Castano A, Movellan J, Vicent MJ. Smart branched polymer drug conjugates as nano-sized drug delivery systems. Biomater Sci. 2015;3(10):1321-1334.

129. Wei H, Zhuo RX, Zhang XZ. Design and development of polymeric micelles with cleavable links for intracellular drug delivery. Prog Polym Sci. 2013;38(3):503-535.

130. Russo A, Degraff W, Friedman N, Mitchell JB. Selective modulation of glutathione levels in human normal versus tumor cells and subsequent differential response to chemotherapy drugs. Cancer Res. 1986 46(6):2845-2848.

131. Shen YQ, Jin EL, Zhang B, et al. Prodrugs forming high drug loading multifunctional nanocapsules for intracellular cancer drug delivery. $J$ Am Chem Soc. 2010;132(12):4259-4265.

132. Zhang HF, Wang JQ, Mao WW, et al. Novel SN38 conjugate-forming nanoparticles as anticancer prodrug: in vitro and in vivo studies. J Control Release. 2013;166(2):147-158.

133. Gou PF, Liu WW, Mao WW, Tang JB, Shen YQ, Sui MH. Selfassembling doxorubicin prodrug forming nanoparticles for cancer chemotherapy: synthesis and anticancer study in vitro and in vivo. J Mater Chem B Mater Biol Med. 2013;1(3):284-292.

134. Brannon-Peppas L, Blanchette JO. Nanoparticle and targeted systems for cancer therapy. Adv Drug Deliv Rev. 2004;56(11):1649-1659.

135. Guo X, Shi CL, Wang J, Di S, Zhou SB. pH-triggered intracellular release from actively targeting polymer micelles. Biomaterials. 2013; 34(18):4544-4554.

136. Zhou YF, Yan DY, Dong WY, Tian Y. Temperature-responsive phase transition of polymer vesicles: real-time morphology observation and molecular mechanism. J Phys Chem B. 2007;111(6):1262-1270

137. Zhou YF, Yan DY. Supramolecular self-assembly of giant polymer vesicles with controlled sizes. Angew Chem Int Ed Engl. 2004;43(37): 4896-4899.

138. Zhou YF, Yan DY. Supramolecular self-assembly of amphiphilic hyperbranched polymers at all scales and dimensions: progress, characteristics and perspectives. Chem Commun (Camb). 2009;(10): $1172-1188$

139. Zhou YF, Huang W, Liu JY, Zhu XY, Yan DY. Self-assembly of hyperbranched polymers and its biomedical applications. Adv Mater. 2010;22(41):4567-4590.

140. Zhu W, Ling J, Shen Z. Synthesis and characterization of amphiphilic star-shaped polymers with calix[6]arene cores. Macromol Chem Phys. 2006;207(9):844-849.

141. Wang F, Bronich TK, Kabanov AV, Rauh RD, Roovers J. Synthesis and characterization of star poly( $\varepsilon$-caprolactone)-b-poly(ethylene glycol) and poly(l-lactide)-b-poly(ethylene glycol) copolymers: evaluation as drug delivery carriers. Bioconjug Chem. 2008;19(7):1423-1429.

142. Hadjichristidis N, Roovers J. Linear viscoelastic properties of mixtures of 3- and 4-arm polybutadiene stars. Polymer. 1985;26(7): $1087-1090$.
143. Pitsikalis M, Pispas S, Mays JW, Hadjichristidis N. Nonlinear block copolymer architectures. Adv Polym Sci. 1998;135(1):1-137.

144. Schultz JL, Wilks ES. Dendritic and star polymers: classification, nomenclature, structure representation, and registration in the DuPont Scion database. J Chem Inf Comput Sci. 1998;38(2):85-99.

145. Kowalczuk A, Stoyanova E, Mitova V, et al. Star-shaped nanoconjugates of cisplatin with high drug payload. Int J Pharm. 2011; 404(1):220-230.

146. Etrych T, Kovář L, Strohalm J, Chytil P, Ŕ́hová B, Ulbrich K. Biodegradable star HPMA polymer-drug conjugates: biodegradability, distribution and anti-tumor efficacy. J Control Release. 2011; 154(3):241-248.

147. Etrych T, Strohalm J, Chytil P, et al. Biodegradable star HPMA polymer conjugates of doxorubicin for passive tumor targeting. Eur J Pharm Sci. 2011;42(5):527-539.

148. Lidický O, Janoušková O, Strohalm J, Alam M, Klener P, Etrych T. Anti-lymphoma efficacy comparison of anti-CD20 monoclonal antibody-targeted and non-targeted star-shaped polymer-prodrug conjugates. Molecules. 2015;20(11):19849-19864.

149. Yang C, Shao QL, Venkataraman S, et al. Structure-directing starshaped block copolymers: supramolecular vesicles for the delivery of anticancer drugs. J Control Release. 2015;208:93-105.

150. Liang Q, Hong CY, Pan CY. Doxorubicin-loaded aromatic iminecontained amphiphilic branched star polymer micelles: synthesis, self-assembly, and drug delivery. Int $J$ Nanomedicine. 2015;10: 3623-3640

151. Sideratou Z, Tsiourvas D, Theodossiou T, Fardis M, Paleos CM. Synthesis and characterization of multifunctional hyperbranched polyesters as prospective contrast agents for targeted MRI. Bioorg Med Chem Lett. 2010;20(14):4177-4181.

152. Gao C, Xu YM, Yan DY, Chen W. Water-soluble degradable hyperbranched polyesters: novel candidates for drug delivery. Biomacromolecules. 2003;4(3):704-712.

153. Prabaharan M, Grailer JJ, Pilla S, Steeber DA, Gong SQ. Folateconjugated amphiphilic hyperbranched block copolymers based on Boltorn H40, poly(l-lactide) and poly(ethylene glycol) for tumortargeted drug delivery. Biomaterials. 2009;30(16):3009-3019.

154. Prabaharan M, Grailer JJ, Pilla S, Steeber DA. Amphiphilic multiarm-block copolymer conjugated with doxorubicin via $\mathrm{pH}$-sensitive hydrazone bond for tumor-targeted drug delivery. Biomaterials. 2009; 30(29):5757-5766.

155. Lutz PJ, Peruch F. Graft copolymers and comb-shaped homopolymers. In: Moeller M, Matyjaszewski K, editors. Polymer Science: A Comprehensive Reference. Amsterdam: Elsevier; 2012:511-542.

156. Xu ZG, Zhang KL, Hou CL, et al. A novel nanoassembled doxorubicin prodrug with a high drug loading for anticancer drug delivery. J Mater Chem B Mater Biol Med. 2014;2(2):3433-3437.

157. Zou J, Yu Y, Li Y, et al. Well-defined diblock brush polymer-drug conjugates for sustained delivery of paclitaxel. Biomater Sci. 2015 3(7):867-874.

158. Tai WY, Mo R, Lu Y, Jiang TY, Gu Z. Folding graft copolymer with pendant drug segments for co-delivery of anticancer drugs. Biomaterials. 2014;35(25):7194-7203.

159. Oh M, Mirkin CA. Chemically tailorable colloidal particles from infinite coordination polymers. Nature. 2005;438(7068):651-654.

160. Hoskins BF, Robson R. Infinite polymeric frameworks consisting of three dimensionally linked rod-like segments. J Am Chem Soc. 1989; 111(15):5962-5964.

161. Tachibana M, Iwaizumi M. EPR and UV-visible spectroscopic studies of copper(II) and cobalt(II) complexes of hydroxyanthraquinones. J Inorg Biochem. 1987;30(2):141-151.

162. Zhou G, Pan J. Polarographic and voltammetric behaviour of ofloxacin and its analytical application. Anal Chim Acta. 1995;307(1):49-53.

163. Xing L, Cao YY, Che SA. Synthesis of core-shell coordination polymer nanoparticles (CPNs) for $\mathrm{pH}$-responsive controlled drug release. Chem Commun (Camb). 2012;48(48):5995-5997.

164. Xing L, Zheng HQ, Che SN. A pH-responsive cleavage route based on a metal-organic coordination bond. Chemistry. 2011;17(26):7271-7275. 
165. Moustaoui H, Movia D, Dupont N, et al. Tunable design of gold (III)doxorubicin complex - PEGylated nanocarrier: the golden doxorubicin for oncological applications. ACS Appl Mater Interfaces. 2016; 8(31):19946-19957.

166. Yang P, Wang HF, Fei G, Yang BS. Antitumor activity of the Cu(II)mitoxantrone complex and its interaction with deoxyribonucleic acid. J Inorg Biochem. 1996;62(2):137-145.

167. Ramaswamy HN, O'Connor RT. Metal complexes of gossypol. J Agric Food Chem. 2002;17(6):752-762.

168. Champion JA, Katare YK, Mitragotri S. Particle shape: a new design parameter for micro- and nanoscale drug delivery carriers. J Control Release. 2007;121(1-2):3-9.

169. Zhang DR, Tan TW, Gao L, Zhao WF, Wang P. Preparation of azithromycin nanosuspensions by high pressure homogenization and its physicochemical characteristics studies. Drug Dev Ind Pharm. 2007; 33(5):569-575

170. Hernández-Trejo N, Kayser O, Steckel H, Müller RH. Characterization of nebulized buparvaquone nanosuspensions-effect of nebulization technology. J Drug Target. 2005;13(8-9):499-507.

171. Kassem MA, Rahman AA, Ghorab MM, Ahmed MB, Khalil RM. Nanosuspension as an ophthalmic delivery system for certain glucocorticoid drugs. Int J Pharm. 2007;340(1-2):126-133.

172. Mouton JW, van Peer A, de Beule K, Van Vliet A, Donnelly JP, Soons PA. Pharmacokinetics of itraconazole and hydroxyitraconazole in healthy subjects after single and multiple doses of a novel formulation. Antimicrob Agents Chemother. 2006;50(12):4096-4102.

173. Crisp MT, Tucker CJ, Rogers TL, Williams RO, Johnston KP. Turbidimetric measurement and prediction of dissolution rates of poorly soluble drug nanocrystals. J Control Release. 2007;117(3):351-359.

174. Kumar MP, Rao YM, Apte S. Improved bioavailability of albendazole following oral administration of nanosuspension in rats. Curr Nanosci. 2007;3(2):191-194.

175. Kumar MP, Rao YM, Apte S. Formulation of nanosuspensions of albendazole for oral administration. Curr Nanosci. 2008;4(1):53-58.

176. Grau MJ, Kayser O, Müller RH. Nanosuspensions of poorly soluble drugs: reproducibility of small scale production. Int J Pharm. 2000; 196(2):155-159.

177. Lee J, Cheng Y. Critical freezing rate in freeze drying nanocrystal dispersions. J Control Release. 2006;111(2):185-192.

178. Hecq J, Deleers M, Fanara D, et al. Preparation and in vitro/in vivo evaluation of nano-sized crystals for dissolution rate enhancement of UCB-35440-3, a highly dosed poorly water-soluble weak base. Eur J Pharm Biopharm. 2006;64(3):360-368.

179. Lee J. Drug nano- and microparticles processed into solid dosage forms: physical properties. J Pharm Sci. 2003;92(10):2057-2068.

180. Badruddoza AZ, Godfrin PD, Myerson AS, Trout BL, Doyle PS. Core-shell composite hydrogels for controlled nanocrystal formation and release of hydrophobic active pharmaceutical ingredients. Adv Healthc Mater. 2016;5(15):1960-1968.

181. Merisko-Liversidge E, Liversidge GG, Cooper ER. Nanosizing: a formulation approach for poorly-water-soluble compounds. Eur $J$ Pharm Sci. 2003;18(2):113-120.

182. Keck CM, Müller RH. Drug nanocrystals of poorly soluble drugs produced by high pressure homogenisation. Eur J Pharm Biopharm. 2006;62(1):3-16.

183. Chandumpai A, Singhpibulporn N, Faroongsarng D, Sornprasit P. Preparation and physico-chemical characterization of chitin and chitosan from the pens of the squid species, Loligo lessoniana and Loligo formosana. Carbohydr Polym. 2004;58(4):467-474.

184. Salazar J, Müller RH, Möschwitzer JP. Combinative particle size reduction technologies for the production of drug nanocrystals. J Pharm (Cairo). 2014;2014:265754.

185. Van Eerdenbrugh B, Van den Mooter G, Augustijns P. Top-down production of drug nanocrystals: nanosuspension stabilization, miniaturization and transformation into solid products. Int J Pharm. 2008;364(1):64-75.
186. Möschwitzer JP. Drug nanocrystals in the commercial pharmaceutical development process. Int J Pharm. 2013;453(1):142-156.

187. Sutradhar KB, Khatun S, Luna IP. Increasing possibilities of nanosuspension. J Nanotechnol. 2013;2013(1):1-12.

188. Sinha B, Müller RH, Möschwitzer JP. Bottom-up approaches for preparing drug nanocrystals: formulations and factors affecting particle size. Int J Pharm. 2013;453(1):126-141.

189. Zhang J, Liang YC, Lin X, et al. Self-monitoring and self-delivery of photosensitizer-doped nanoparticles for highly effective combination cancer therapy in vitro and in vivo. ACS Nano. 2015;9(10):9741-9756.

190. Chan HK, Kwok PC. Production methods for nanodrug particles using the bottom-up approach. Adv Drug Deliv Rev. 2011;63(6):406-416.

191. Chen JF, Zhang JY, Shen ZG, Zhong J, Yun J. Preparation and characterization of amorphous cefuroxime axetil drug nanoparticles with novel technology: high-gravity antisolvent precipitation. Ind Eng Chem Res. 2006;45(25):8723-8727.

192. Sarkari M, Brown J, Chen X, Swinnea S, Williams RO 3rd, Johnston KP. Enhanced drug dissolution using evaporative precipitation into aqueous solution. Int J Pharm. 2002;243(1-2):17-31

193. Montes A, Gordillo MD, Pereyra C, de la Ossa EJ. Particles formation using supercritical fluids. In: Nakajima H, editor. Mass Transfer: Advanced Aspects. Rijeka: Intech; 2011:461-480.

194. Girotra P, Singh SK, Nagpal K. Supercritical fluid technology: a promising approach in pharmaceutical research. Pharm Dev Technol. 2013;18(1):22-38.

195. Gao L, Zhang DR, Chen MH. Drug nanocrystals for the formulation of poorly soluble drugs and its application as a potential drug delivery system. J Nanopart Res. 2008;10(5):845-862.

196. Chang TL, Zhan H, Liang D, Liang JF. Nanocrystal technology for drug formulation and delivery. Front Chem Sci Eng. 2015;9(1):1-14.

197. Li W, Zhang XJ, Hao XJ, Jie JS, Tian BS, Zhang XH. Shape design of high drug payload nanoparticles for more effective cancer therapy. Chem Commun (Camb). 2013;49(93):10989-10991.

198. Dobrovolskaia MA, Aggarwal P, Hall JB, Mcneil SE. Preclinical studies to understand nanoparticle interaction with the immune system and its potential effects on nanoparticle biodistribution. Mol Pharm. 2008;5(4):487-495.

199. Li W, Yang YL, Wang C, et al. Carrier-free, functionalized drug nanoparticles for targeted drug delivery. Chem Commun (Camb). 2012; 48(65):8120-8122.

200. Zhou M, Zhang X, Yang Y, et al. Carrier-free functionalized multidrug nanorods for synergistic cancer therapy. Biomaterials. 2013; 34(35):8960-8967.

201. Huang P, Wang DL, Su Y, et al. Combination of small molecule prodrug and nanodrug delivery: amphiphilic drug-drug conjugate for cancer therapy. J Am Chem Soc. 2014;136(33):11748-11756.

202. Huang P, Hu M, Zhou L, et al. Self-delivery nanoparticles from an amphiphilic covalent drug couple of irinotecan and bendamustine for cancer combination chemotherapy. RSC Adv. 2015;5(105): 86254-86264.

203. Zhang T, Huang P, Shi LL, et al. Self-assembled nanoparticles of amphiphilic twin drug from floxuridine and bendamustine for cancer therapy. Mol Pharm. 2015;12(7):2328-2336.

204. Hu MX, Huang P, Wang Y, et al. Synergistic combination chemotherapy of camptothecin and floxuridine through self-assembly of amphiphilic drug-drug conjugate. Bioconjug Chem. 2015;26(12): 2497-2506.

205. Imaz I, Rubio-Martínez M, An JH, Solé-Font I, Rosi NL, Maspoch D. Metal-biomolecule frameworks (MBioFs). Chem Commun (Camb). 2011;47(26):7287-7302.

206. McKinlay AC, Morris RE, Horcajada P, et al. BioMOFs: metal-organic frameworks for biological and medical applications. Angew Chem Int Ed Engl. 2010;49(36):6260-6266.

207. Miller SR, Heurtaux D, Baati T, Horcajada P, Grenèche JM, Serre C. Biodegradable therapeutic MOFs for the delivery of bioactive molecules. Chem Commun (Camb). 2010;46(25):4526-4528. 
208. An JH, Geib SJ, Rosi NL. Cation-triggered drug release from a porous zinc-adeninate metal-organic framework. J Am Chem Soc. 2009; 131(24):8376-8377.

209. Lin WB, Rieter WJ, Taylor KM. Modular synthesis of functional nanoscale coordination polymers. Angew Chem Int Ed Engl. 2009; 48(4):650-658.

210. Della RJ, Liu D, Lin WB. Nanoscale metal-organic frameworks for biomedical imaging and drug delivery. Acc Chem Res. 2011;44(10): 957-968.

211. Taylor-Pashow KM, Della RJ, Huxford RC, Lin WB. Hybrid nanomaterials for biomedical applications. Chem Commun (Camb). 2010; 46(32):5832-5849.

212. Rieter WJ, Pott KM, Taylor KM, Lin WB. Nanoscale coordination polymers for platinum-based anticancer drug delivery. J Am Chem Soc. 2008;130(35):11584-11585.

213. Huxford RC, Dekrafft KE, Boyle WS, Liu D, Lin WB. Lipid-coated nanoscale coordination polymers for targeted delivery of antifolates to cancer cells. Chem Sci. 2012;3(1):198-204.

214. Li K, Liu H, Gao W, et al. Mulberry-like dual-drug complicated nanocarriers assembled with apogossypolone amphiphilic starch micelles and doxorubicin hyaluronic acid nanoparticles for tumor combination and targeted therapy. Biomaterials. 2015;39:131-144.
215. Deng ZJ, Morton SW, Ben-Akiva E, Dreaden EC, Shopsowitz KE, Hammond PT. Layer-by-layer nanoparticles for systemic codelivery of an anticancer drug and siRNA for potential triple-negative breast cancer treatment. ACS Nano. 2013;7(11):9571-9584.

216. Rösslein M, Liptrott NJ, Owen A, Boisseau P, Wick P, Herrmann IK. Sound understanding of environmental, health and safety, clinical, and market aspects is imperative to clinical translation of nanomedicines. Nanotoxicology. 2017;11(2):147-149.

217. Batrakova EV, Kabanov AV. Pluronic block copolymers: evolution of drug delivery concept from inert nanocarriers to biological response modifiers. J Control Release. 2008;130(2):98-106.

218. Elkinson S, Keating GM. Lixisenatide: first global approval. Drugs. 2013;73(4):383-391

219. Kornblum N, Ayyanar K, Benimetskaya L, Richardson P, Iacobelli M, Stein CA. Defibrotide, a polydisperse mixture of single-stranded phosphodiester oligonucleotides with lifesaving activity in severe hepatic veno-occlusive disease: clinical outcomes and potential mechanisms of action. Oligonucleotides. 2006;16(1):105-114.

220. Syed YY. Rucaparib: first global approval. Drugs. 2017;77(5): 585-592.
International Journal of Nanomedicine

\section{Publish your work in this journal}

The International Journal of Nanomedicine is an international, peerreviewed journal focusing on the application of nanotechnology in diagnostics, therapeutics, and drug delivery systems throughout the biomedical field. This journal is indexed on PubMed Central, MedLine, CAS, SciSearch $®$, Current Contents $\AA /$ Clinical Medicine,

\section{Dovepress}

Journal Citation Reports/Science Edition, EMBase, Scopus and the Elsevier Bibliographic databases. The manuscript management system is completely online and includes a very quick and fair peer-review system, which is all easy to use. Visit http://www.dovepress.com/ testimonials.php to read real quotes from published authors. 